\title{
DISEÑO CONSTITUCIONAL E IMPLEMENTACIÓN DE LA FEDERACIÓN CANADIENSE: DE MACDONALD A HARPER
}

\author{
ESTHER SEIJAS VILLADANGOS \\ Profesora Titular de Derecho Constitucional \\ Universidad de León
}

\begin{abstract}
SUMARIO
I. Diseño constitucional del Estado federal canadiense.

II. Implementación del modelo constitucional: la realidad de la federación canadiense.

III. Reflexión final: principales retos para el futuro del federalismo canadiense.
\end{abstract}

"La génesis del sistema federal en Canadá fue un compromiso político entre defensores de la unidad (quienes habrían preferido una unión legislativa) y defensores de la diversidad (aquellos que no deseaban renunciar a las identidades diferenciadas de sus provincias)" ${ }^{1}$. El consenso, el compromiso, el pacto es una idea que subyace en todo Estado federal, lo que hace diferentes a las federaciones es cómo implementan ese pacto. En el caso del federalismo canadiense los referentes de origen fueron básicamente dos: la Constitución norteamericana y el sistema parlamentario de la metrópoli; a partir de esas dos cotas se ha erigido un federalismo que podríamos caracterizar como flexible, «ambivalente ${ }^{2}$, poliédrico, en la medida que ha amalgamado intereses y componentes muy distintos ${ }^{3}$ e, igual-

1 HOGG, P., Constitutional Law of Canada, Thomson-Carswell, Toronto, 2008 (student edition), pág. 124.

2 BAKVIS, H., BAIER, G. y BROWN, D., Contested federalism. Certainty and ambiguity in the Canadian federation, Oxford University Press, Ontario, 2009, pág. 246.

3 WATTS, R., Sistemas federales comparados, Marcial Pons, Madrid, 2006 (Trad. y estudio introductorio E. SEIJAS VILLADANGOS), pág. 121. 
mente, en cuanto que su evolución se ha gestado desde el patrón constitucional hacia un sistema de organización territorial en el que distintos factores han ido imprimiendo su huella: el protagonismo de los primeros ministros - a ellos se hace una referencia diacrónica en el título que encabeza este estudio-; la jurisprudencia del Tribunal Supremo; las distintas composiciones del Parlamento federal y de las Asambleas legislativas provinciales y, finalmente, un rico y complejo entramado negociador que en un afán simplificador, sólo justificable por motivos expositivos, podríamos denominar relaciones intergubernamentales. Por consiguiente, lo que vamos a afrontar en este ensayo es una aproximación a esa dualidad intrínseca al federalismo canadiense, teoría versus realidad, diseño constitucional versus implementación del modelo. Esta tensión se ha reificado en distintas fórmulas federales, a veces, incluso opuestas (federalismo cooperativo versus federalismo competitivo; federalismo ejecutivo versus federalismo legislativo; federalismo simétrico versus federalismo asimétrico) que serán la guía de este estudio, diversas percepciones que convergen en una: la federación canadiense.

\section{DISEÑO CONSTITUCIONAL DEL ESTADO FEDERAL CANADIENSE}

La afirmación de que la Constitución canadiense "quizá no sea una Constitución federal ideal ${ }^{4}$ lejos de desalentar su utilización como recurso para comprender el federalismo canadiense nos insta a recurrir a su complejidad como un primer estadio en este recorrido por el federalismo en Canadá, a partir de la asignación de distintos atributos al federalismo o a los federalismos diseñados en ella. No obstante, lo que primero capta nuestra atención es que el propio constituyente canadiense se vea obligado a definir en el art. 52.2 de la Ley Constitucional de 1982, qué es la Constitución de Canadá5. Ésta incluye tres categorías de instrumentos normativos: la primera es la propia Ley Constitucional de 1982; la segunda está constituida por una lista de 30 leyes y disposiciones normativas, incluidas en forma de anexo a esta ley, entre las que se referencia la Ley Constitucional de 1867, Acta de América del Norte Británica, y sus reformas, así como las leyes de admisión y creación de nuevas provincias, e incluso el Estatuto de Westminster de 1931; en tercer lugar, forman parte de la Constitución canadiense todas aquellas reformas que desde 1982 hayan podido hacerse a las normas referidas y las que se

4 BAKVIS, H., BAIER, G. y BROWN, D., Contested federalism. Certainty and ambiguity in the Canadian federation, ob. cit., pág. 70.

5 "La Constitución de Canadá comprende:

a) La Ley de 1982 sobre Canadá, incluida la presente ley;

b) Los textos legislativos y los decretos incorporados en el Anexo;

c) Las modificaciones de los textos legislativos y de los decretos mencionados en los apartados a) y b)." 
harán en el futuro ${ }^{6}$. La dualidad a la que hacíamos referencia en la introducción aflora de modo expreso en esta definición doctrinal de Constitución que se integra en su literalidad, la tradición británica y la quiebra de la misma por la que se apostó en la emancipación norteamericana de la metrópoli, tradición y codificación. Sin embargo esta definición de Constitución no es gratuita, ni un mero apoyo pedagógico, sino que se convierte en una pieza clave para definir, por un lado, la supremacía de la Constitución canadiense (art. 52.1) y, por otro, su rigidez (52.3), ambos pilares decisivos en el diseño del federalismo, un federalismo que desde la Constitución se nos presenta con los siguientes atributos: dual, colonial, asimétrico y renovado.

\section{I.1. Federalismo dual: el ReParto Constitucional De PODERES}

El federalismo dual ha protagonizado una de las dialécticas más relevantes en la explicación del federalismo, "federalismo dual" versus "federalismo cooperativo". En cierto modo, podríamos pensar que a partir de ese binomio la creatividad de los autores y la evolución de los acontecimientos en cada Estado federal han abonado el terreno para las restantes nuevas construcciones dogmáticas en la materia. El federalismo dual es el resultado de la concepción de la Constitución como un convenio o un acuerdo entre Estados, en virtud del cual éstos mantienen una soberanía inviolable sobre muchos ámbitos de actuación 7 . El gobierno central se convierte así en una instancia cuyos poderes son tasados, derivando hacia una tensa relación entre niveles de gobierno. El símil con el que se ha descrito es el de la tarta de estratos o capas (layer cake), en la cual los diferentes ingredientes y sabores se han ordenado horizontalmente y se hallan perfectamente separados ${ }^{8}$. Es frecuen-

6 Las reformas habidas hasta el momento son las diez siguientes: (1983) Proclamación de Reforma de la Constitución que reformó el art. 25. b y agregó los artículos 35(3), 35(4), 35.1, 37.1 y 54.1 de la Ley Constitucional de 1982. Esta reforma se aprobaría por el Parlamento y por nueve Asambleas Legislativas, todas a excepción de Québec; (1985) Ley Constitucional, en materia de representación afectaría al art. 51 de la Ley Constitucional de 1867; (1987) Ley de Terranova que hace referencia a los derechos de las escuelas confesionales; (1993) Ley de Nuevo Brunswick, agregando el art. 16.1 a la Carta de Derechos, con referencia a la igualdad de status y de derechos de las comunidades lingüísticas francesa e inglesa de Nuevo Brunswick; (1993) Isla del Príncipe Eduardo, en el sentido de permitir que un puente fijo supla el servicio de ferry en su conexión con el continente; (1997) Ley de Terranova, relativa a la educación religiosa; (1997) Québec, reformando el art. 93 de la Ley Constitucional de 1867 en el sentido de que las disposiciones relativas a la especial protección de las escuelas confesionales no se apliquen a Québec; (1998) Terranova, relativa a la educación religiosa; (1999) Nuvavut, estableciendo la representación del nuevo Territorio de Nuvavut en el Senado y en la Cámara de Representantes y (2001) Terranova y Labrador, cambiando la denominación de la Provincia.

7 MADISON, Paper 39, en El federalista, FCE, Méjico, 1957, pág. 158 (ed. orig. 1788).

8 La metáfora de la tarta de estratos se atribuye a M. GRODZINS. La crítica al mismo deriva de sus connotaciones estáticas, el modelo de autoridad separada es obsoleto e irrelevante, dado que en la realidad no existen las condiciones políticas y sociales que presume el modelo. El alter lo encontramos en el federalismo cooperativo, el que asociamos con una tarta jaspeada (marble 
te atribuir a Corwin la paternidad de este calificativo al federalismo9, al que describe, en un tributo a la Escuela formalista en la que junto a Wheare se incluiría $^{10}$, como con el que en 1787 se identificaba la gran masa del pueblo americano, cuyos intereses eran fundamentalmente locales, donde el gobierno nacional y los estatales se consideraban como rivales, siendo el principal deber del Tribunal Supremo mantener esa diferencia entre los dos centros de poder $^{11}$.

La inspiración estadounidense que impregnó la redacción de la renombrada Ley Constitucional de 1867 deja su huella principal en la inspiración del diseño dual con el que se ejecuta el reparto competencial en la misma. La apuesta por un doble listado de poderes exclusivos federales y provinciales, regulados respectivamente en los artículos 91 y 92, lo constata. La gran diferencia con el precedente americano es el carácter explícito y exhaustivo del doble listado, frente a la opción de 1787 que luego emularían los australianos en 1901 — rechazando el modelo canadiense más próximo en el tiempo- de incluir la relación de competencias de un nivel de gobierno para asignar al otro los poderes que residualmente se desarrollen.

El artículo 91 de la Ley Constitucional efectúa la relación de un total de veintiocho competencias (deuda y propiedades públicas; reglamentación del tráfico y del comercio; tributos; deuda pública; servicio postal, censo y estadística; servicio militar y defensa; función pública; navegación; cuarentena, establecimiento y mantenimiento de los hospitales de guerra; pesca marítima, fluvial y lacustre; política monetaria y acuñación de moneda; sistema bancario; cajas de ahorro; pesos y medidas; letras de cambio y pagarés; interés

cake) o con una tarta arco iris (rainbow cake). Las vetas de aspecto marmóreo, verticales y diagonales, los remolinos se corresponden a lo que también se ha denominado "modelo de autoridad superpuesta" (WRIGHT) o "federalismo de nuevo estilo" (REAGAN y SANZONE). El principio fundamental es que los poderes y las funciones de las entidades de gobierno central, regional y local son compartidas. Cfr. LÓPEZ ARANGUREN, E., El federalismo americano: las relaciones entre poderes en los Estados Unidos, Instituto de Estudios de la Administración Local, Madrid, 1987, págság. 37-49.

9 BASSANI, L.M., STEWART, W. y VITALE, A., I concetti del federalismo, Giuffrè Editore, Milano, 1995, pág. 177.

10 El carácter legal y formal de las primeras aproximaciones doctrinales al federalismo puede ilustrarse con la obra de CORWIN. El principal argumento de CORWIN consiste en describir el federalismo — en particular el federalismo americano- exclusivamente a partir de la interpretación que el Tribunal Supremo ha realizado del "federal article", el art. IV de la Constitución de los Estados Unidos de América. Cfr. CORWIN, E. S., The Constitution and what it means today, Princeton, New Jersey, Princeton University Press, 1948, págs. 135 y ss. Existe una edición en español traducida por A. LEAL. CORWIN, E. S., La Constitución de los Estados Unidos y su significado actual, Editorial Fraterna, Buenos Aires, 1987. Las consecuencias que extrae son básicamente dos: el predominio del gobierno nacional en el sistema de relaciones que se articula dentro de los Estados federales y la necesaria igualdad entre los Estados miembros de la federación. Ibídem, idem: "This union is a union of equal States", ss. la jurisprudencia del Tribunal Supremo. V. gr. Coyle vs. Oklahoma (1911) y Stearns vs. Minnessota (1900). CORWIN, E. S., The higher law background of american Constitutional Law, Great Seal Books, New York, 1961, pág. 5 .

11 BASSANI, L.M., STEWART, W. y VITALE, A., I concetti del federalismo, ob. cit., pág. 177. 
monetario; licitaciones públicas; bancarrota y quiebra; patentes de invención; derechos de autor; indígenas y sus tierras; extranjería; matrimonio y divorcio; derecho penal y penitenciario) sobre las que el parlamento federal ejerce una autoridad legislativa de modo exclusivo. El parlamento tiene una competencia general, que encabeza la exhaustiva relación citada, para la aprobación de leyes para la "paz, el orden y el buen gobierno de Canadá", conocida como la cláusula POGG, merced a la cual el gobierno federal puede ampliar sus potestades más allá de las materias citadas, siempre y cuando no se trate de competencias atribuidas en exclusiva a las provincias. En ese espacio, el sentido residual de este aserto (reforzado con lo regulado en el apartado 29 del mismo artículo 91 donde se atribuye al Parlamento federal toda materia que no sea de competencia de los legislativos provinciales) permitirá legislar desde el nivel federal más allá de las veintiocho competencias referidas.

Por su parte el artículo 92 regula las competencias exclusivas de los legislativos provinciales (tributos provinciales; función pública provincial; deuda provincial; tierras públicas; prisiones; sanidad y sistema de hospitales; instituciones municipales; derechos sobre locales de ocio; determinados trabajos y empresas de carácter local; celebración del matrimonio en la provincia; propiedad y derechos civiles en la provincia; administración de justicia a nivel provincial; ejecución de penas con el objeto de hacer cumplir la legislación provincial y todas aquellas de naturaleza exclusivamente local o privada en la provincia, como la educación).

Este sistema dual presenta aspectos positivos y negativos. Entre los primeros es reseñable la meridiana claridad con la que se concibe el reparto de poder, de la que presuntamente derivaría una merma en la posterior conflictividad. Entre los segundos es previsible que las circunstancias y los ámbitos materiales sobre los que los legislativos han de ejercer sus funciones cambien, de modo que un listado cerrado tenga dificultades para adelantarse y prever esos cambios por lo que el riesgo de obsolescencia es muy elevado. La realidad ha desvelado que en la práctica los gobiernos se ven obligados a cooperar, por lo que esa drástica dualidad o taxativos blindajes son utópicos e irreales, aunque las discrepancias son importantes ${ }^{12}$.

12 La redacción original de la British North America Act especificaba dos ámbitos de legislación concurrente, inmigración y agricultura, en los que en caso de conflicto primaría la legislación estatal. Igualmente, el derecho penal se concebía como un terreno competencial compartido, donde se asignaba legislación al poder federal y ejecución al provincial. La percepción discrepante de este modo de reparto competencial la hallamos en el reciente trabajo de BAKVIS, BAIER y BROWN quienes sostienen que el "resultado del mismo ha sido un sistema que continúa poniendo mucho más énfasis en la autonomía de las unidades constituyentes de lo que lo hacen otras federaciones, donde la legislación concurrente o federal actúa como una constante restricción a las actuaciones de las provincias o estados". BAKVIS, H., BAIER, G. y BROWN, D., Contested federalism. Certainty and ambiguity in the Canadian federation, opág. cit., pág. 250. 


\section{I.2. Federalismo colonial: gobierno Central fuerte versus provincias SUBORDINADAS}

El atributo de colonial con el que se describe el federalismo ideado por los padres de la federación es un neologismo que acuñamos en estas líneas, conceptualmente próximo a un federalismo hegemónico ${ }^{13}$, pero con matices derivados de la génesis del federalismo canadiense ${ }^{14}$ y de sus antecedentes ${ }^{15}$.

Dos son las manifestaciones principales que explicitan este carácter colonial que se advierte en la redacción original de la Ley de América del Norte Británica de 1867: la configuración de un gobierno central fuerte y la subordinación de las provincias al centro.

Los principales indicadores de la fortaleza con la que se concibió el gobierno central los podemos sintetizar en los siguientes: a) asignación del poder residual al parlamento federal. Esta desviación respecto al precedente americano, donde el poder residual se había otorgado a los estados, se justifica fundamentalmente por el temor a evitar la secesión - recordemos que en el período constituyente canadiense los americanos tenían muy reciente la guerra civil - causa principal del desmoronamiento de una federación; b) la atribución como competencias federales de algunas materias que habían sido atribuidas a los estados en la Constitución americana. Por ejemplo, art. 91.2, la regulación del tráfico y del comercio $^{16}$; sistema bancario, art. 91.15; régimen legal del matrimonio y de su disolución, art. 91.26; derecho penal, art. 91.27 y régimen penitenciario, art. 91.28. c) El gobierno federal fue configurado como fiscalmente dominante, otorgándose al parlamento federal la competencia para la exacción de impuestos tanto directos como indirectos (art. 91.3, fijación de tributos por cualquier modo o manera de imposición), mientras que a

13 BASSANI, L.M., STEWART, W. y VITALE, A., I concetti del federalismo, ob. cit., pág. 186.

14 En palabras de HOGG, "en el momento en el que se produjo la unión de las colonias británicas del norte de América proliferó una inclinación favorable a la unión legislativa. John. A. Macdonald deseaba una unión legislativa, como otros muchos en el Alto Canadá (que se convertiría en Ontario). Pero tuvieron que aceptar una federación porque el Bajo Canadá (que se transformaría en Quebec) y las provincias marítimas de Nuevo Brunswick, Nueva Escocia y la Isla del Príncipe Eduardo no habrían accedido a una unión legislativa. El Bajo Canadá temía el que si se unía bajo la forma de una unión legislativa, su lengua francesa, su cultura y sus instituciones y su religión católica se verían amenazadas por la mayoría protestante angloparlante». Es preciso aclarar que la "unión legislativa" hace referencia a una unión de estados o provincias que daría lugar a un nuevo Estado que incorporaría las unidades preexistentes y las sometería a la autoridad de un legislativo central único. El ejemplo más relevante es el Reino Unido que se presenta como la unión legislativa de Inglaterra, Gales, Escocia e Irlanda del Norte. Cfr. HOGG, P., Constitutional Law of Canada, ob. cit. , pág. 116.

15 La pertenencia de Canadá al Imperio Británico pesa de modo decisivo en esta descripción de federalismo colonial al reproducir en su interior pautas competenciales del Imperio.

16 El artículo I, Sección VIII, 3, de la Constitución de los Estados Unidos de América de 1787 establece como competencia del Congreso la reglamentación del comercio con las naciones extranjeras, entre los diferentes estados y con las tribus indias. Sin embargo, la Ley Constitucional canadiense no establece ninguna acotación en su atribución federal de las competencias en materia de comercio. 
las provincias se les limitó sus facultades fiscales a la exacción de impuestos directos (art. 92.2).

La subordinación de las provincias al centro se evidencia a través de las siguientes constataciones: a) la potestad del parlamento federal de extender su legislación al ámbito provincial con la consiguiente reforma y anulación de su legislación (art. 90); b) la potestad del ejecutivo federal de nombrar un Lugarteniente-Gobernador en cada provincia (art. 58), vetándose la capacidad de las provincias para reformar esa parte de sus constituciones (art. 92.1) ${ }^{17}$; c) el art. 96 atribuye al gobierno federal la potestad para nombrar a los jueces de los tribunales superiores, de distrito y de los condados de cada provincia; d) en el art. 93 se asigna al gobierno federal la facultad para dilucidar los recursos de apelación que afecten a los derechos educativos de las minorías y al parlamento federal se le asignó la facultad de fortalecer una decisión impugnada en esa materia mediante la aprobación de "remedial laws" (leyes compensatorias); e) por los artículos 91.29 y 92.10 se asignó al parlamento federal la competencia unilateral de incluir la actividad local dentro del marco legislativo federal simplemente por la mera declaración de que estos son "de interés general para Canadá" "

Esta disparidad en la posición competencial de la federación y las provincias se concebía como el mejor modo de asegurar la viabilidad de la federación. Empero, esas competencias menores, como sanidad o educación, conferidas a las provincias han evidenciado ser de vital importancia y con ello la quiebra de las previsiones de los padres de la federación, así como el declinar de ese federalismo colonial.

\section{I.3. Federalismo asimétrico en la constitución}

Adentrarnos en el estudio del diseño constitucional del federalismo canadiense de la mano del federalismo asimétrico es una tarea más compleja de lo que a priori pudiera parecer. Es cierto que la tensión entre mayoría y minoría ${ }^{19}$, entre unidad y diversidad, entre simetría y asimetría ${ }^{20}$, ha presidido

17 Este precepto sería anulado por la Ley Constitucional de 1982, que por su parte permite en su art. 45 la competencia exclusiva de la asamblea legislativa provincial para reformar la Constitución de su provincia, aunque el art. 41 mantenga la reserva federal en lo concerniente al Lugarteniente-Gobernador.

18 Ninguna de estas competencias es de carácter federal en la Constitución norteamericana. Cfr. HOGG, P., Constitutional Law of Canada, ob. cit. , pág. 127.

19 WOEHRLING, J., "Evolució de les relacions entre el Quebec i el Canadà anglès de 1867 als nostres dies", en Seminari sobre el federalisme canadenc, Institut d’Estudis Autonòmics, Barcelona, 1992, pág. 252.

20 Pese a renunciar a insertar una introducción conceptual sobre la naturaleza y la tipología de asimetrías, sin embargo su referencia es un mínimun exigible para la comprensión del epígrafe. La asimetría para el Derecho Constitucional supone una modalidad de estructuración estatal que presentan determinados Estados en los que los entes territoriales dotados de autonomía política que lo componen disfrutan de un trato constitucional diferenciado, legitimado en el re- 
toda la trayectoria constitucional canadiense. Empero, únicamente desde una singular conexión de preceptos constitucionales puede "especularse" ${ }^{21}$ sobre las facetas asimétricas del federalismo en Canadá.

El primer paso radica en evidenciar la existencia de pre-requisitos asimétricos sobre los que se erige la Constitución de $1867^{22}$. Desde los primeros contactos de tipo colonial con un territorio que se describió, interpretando las referencias de los aborígenes que lo habitaban, con una palabra que a duras penas entendieron y que se transcribió como Caignedaze ${ }^{23}$, el dualismo anglofrancés ha marcado toda la trayectoria política y jurídica de Canadá. Desde Francia se legaría a Canadá la lengua francesa, la religión católica y su derecho civil escrito. La herencia británica se podría sucintamente condensar en una religión, la anglicana, en una lengua, el inglés, y en un sistema jurídico, el common law.

La Ley Constitucional de 1867 introduce una novedad decisiva: la incorporación a su contenido (jurídico) de algunas de las diferencias existentes entre las provincias que inicialmente componían Canadá ${ }^{24}$. Esta vertiente diferenciadora de la Ley Constitucional de 1867 puede desglosarse en los siguientes ámbitos materiales: ordenamiento jurídico privado, representación en el Senado y tratamiento de las minorías lingüísticas y religiosas.

\section{a) Ordenamiento jurídico privado}

La constatación de la existencia de una asimetría de titularidad quebequesa en el sistema jurídico-privado diseñado por la Constitución de 1867 implica efectuar, inicialmente, un ejercicio de superposición de dos artículos

conocimiento positivo de disponer de singularidades de diversa índole (lingüísticas, culturales, jurídicas o financieras) con relación a los restantes componentes del Estado. En otros términos, se trataría de la interpretación de las consecuencias que derivan del reconocimiento constitucional de ciertas particularidades específicas o propias de determinados territorios. Sic. TRUJILLO, G., "Integración constitucional de los hechos diferenciales y preservación de la cohesión básica del Estado autonómico", en VV. AA., Asimetría y cohesión en el Estado autonómico, INAP, Madrid, 1997, pág. 18; SEIJAS VILLADANGOS, E., "Un nuevo estadio en el discurso federal: el federalismo asimétrico", en Pensamiento Constitucional, Perú, Universidad Católica de Lima, 2000, págs. 343-386; SEIJAS VILLADANGOS, E., Configuración asimétrica del sistema de Comunidades Autónomas, Universidad de León, León, 2001.

21 TARLTON, CH. D., "Symmetry and asymmetry as elements of federalism: a theoretical speculation", en The Journal of Politics, Vol. 27, n. ${ }^{\circ} 4$, 1965, págs. 861-864.

22 LOWER, A.R.M., Colony to Nation: A History of Canada, 4.. ${ }^{a}$ edic., Longmans, Toronto, 1964, págs. 47-63.

23 STOKESBURY, J., "La época de expansión y exploración", en STOKESBURY, J., MOODY, B. y BALDWIN, D., Así nació Canadá, en Cuadernos de Historia 16, n. ${ }^{\circ} 270$, pág. 7.

24 La ambigüedad con que se produce ese reconocimiento constitucional de ciertas particularidades específicas o propias de una u otra provincia y de las potenciales consecuencias de tal reconocimiento dificulta una catalogación monolítica de Constitución asimétrica. Cfr. SAIZ ARNAIZ, quien afirma que no estamos ante una Constitución asimétrica, puesto que "la Constitución de Canadá no otorga a Quebec un plus de poderes o "estatuto particular" que diferencie a dicha Provincia de las demás integradas en la Federación. No hay, por tanto, asimetría de Derecho". SAIZ ARNAIZ, A., "Asimetría y Estado federal en Canadá", en R.V.A.P., n. ${ }^{\circ}$ 47(II), pág. 231. 
clave: el art. 94 y el art. 129 LC. Mientras el art. 94 dispone la posibilidad de que el Parlamento federal proceda a uniformizar total o parcialmente las Leyes de las provincias de Ontario, Nueva Escocia y Nuevo Brunswick, en materia de propiedad, derechos civiles y procedimiento judicial. El silencio constitucional con respecto a Quebec ${ }^{25}$ generaría una situación asimétrica, traducible en la imposibilidad de proceder a la uniformización de su sistema jurídico privado con las restantes provincias. A mayor abundamiento, el art. $129^{26}$ prevé la continuidad del sistema legal existente, pero no sólo en las tres Provincias citadas, sino "expresamente" también en Quebec.

En esta línea argumental ha de incardinarse el art. 92.13 LC 1867, referente a los poderes exclusivos de los legislativos provinciales, que incorpora el título clave de la "propiedad y derechos civiles en la provincia" ${ }^{27}$. El compendio de estos tres artículos hace posible la vigencia del sistema de derecho civil quebequés, de inspiración francesa, diferenciado del common law de las restantes provincias anglófonas. Circunstancia ésta de la que se puede derivar la defensa de la existencia de una asimetría de iure - sistema de Derecho Civil codificado-, si bien implícitamente regulada en la Constitución, fruto del silencio del art. 94 y de la correlativa inclusión de Quebec en el art. 129.

La proyección institucional de esta asimetría se materializa en los arts. 97 y 98 LC 1867 donde se diferencian dos ámbitos de procedencia de los jueces, el de las provincias de common law, subdividido entre sí por provincias (Ontario, Nueva Escocia y Nuevo Brunswick) hasta que no se proceda a unificar su legislación en lo referido a propiedad y derecho civil, y el del derecho civil quebequés, que perpetua su singularidad asimétrica, al margen de las vicisitudes uniformizadoras del Canadá anglófono (art. 98).

\section{b) Representación en el Senado}

La representación en el Senado de las diferentes Provincias y Territorios que componen Canadá se regula en los arts. 22 y 23 LC 1867. El sistema de representación adoptado es complejo, algo coherente a tenor de la realidad

25 Esta opción es un hipotético futurible que aún no se ha implementado, frente a un Quebec que sí ha procedido a codificar su sistema de derecho civil: Code Civil (1866), Code de procédure civile (1867) y el Proyecto de Ley 125, Code civil de Québec (1991), que entró en vigor el 1 de junio de 1994. Vid. ARROYO i AMAYUELAS, E., "El Derecho Civil en Quebec: Codificación y Recodificación", en MITJANS, E. Y CASTELLÁ, J. M. (Coords.), Canadá. Introducción al sistema político y jurídico, Publicacions de la Universitat de Barcelona, Barcelona, 2001, págs. 283-328.

26 Art. 129: "Dejando a salvo las excepciones establecidas en la presente Ley, todas las Leyes en vigor en Canadá, Nueva Escocia o Nuevo Brunswick, en la Unión, en todos los Tribunales de la Jurisdicción Civil y Penal, y todas las Comisiones legales, Poderes y Autoridades, y en todo el sistema funcionarial Judicial, Administrativo o Ministerial continuarán en Ontario, Quebec, Nueva Escocia y Nuevo Brunswick, respectivamente (...) wla cursiva es nuestra-.

27 Es necesario matizar que la amplitud de este título se ve recortada por el contenido del art. 91 LC 1867, que señala los poderes del Parlamento federal canadiense incluyendo aspectos tan importantes como: comercio (apdo. 2), sistema bancario (apdos. 15 y 16), quiebra e insolvencia (apdo. 21), patentes (apdo. 22) o matrimonio y divorcio (apdo. 26). 
a representar. Su diseño ha sido objeto de numerosas propuestas de refor$\mathrm{ma}^{28}$, algo que evidencia la insatisfacción general que suscita. La Constitución diseña cuatro "Provincias Senatoriales" (art. 22) a las que se asigna de forma igualitaria un total de veinticuatro senadores: Quebec, Ontario, Las Provincias Marítimas y Las Provincias del Oeste. Esa paridad formal quiebra cuando se constata que sólo Quebec y Ontario son efectivamente provincias, siendo las dos restantes artificios legales - Regiones, en un Estado federal- de difícil encaje cuantitativo, a partir de las variables tradicionales de espacio y población. En este sentido, la única asimetría defendible es una asimetría de facto que prima a las dos grandes Provincias.

Desde una perspectiva de iure el interrogante que se plantea es el de si las dos previsiones que in fine efectúan ambos artículos en relación a Quebec son susceptibles de calificarse como asimetrías. El art. 22 establece que los veinticuatro senadores correspondientes a Quebec sean designados ${ }^{29}$ por cada una de las veinticuatro divisiones electorales del Bajo Canadá y el art. 23 (6), relativo a los requisitos de los senadores, obliga correlativamente con esa subdivisión a que los senadores "en el caso de Quebec" se vinculen mediante su residencia o título de propiedad a la subdivisión por la que son designados. Así, si incardinamos su existencia en un contexto más amplio, el de la diferencialidad de Quebec, asistiríamos a una auténtica asimetría constitucional.

\section{c) Disposiciones relativas a los derechos de las minorías}

La Constitución de 1867 protege dos facetas decisivas para la identificación de las minorías, la lingüística y la religiosa, que se funden en el terreno educativo.

La disposición tuitiva en materia lingüística dispensada por la LC 1867 se concreta en el contenido de su art. 133. En éste se dispone que tanto la lengua inglesa como la francesa podrán ser usadas («may be used/l'usage sera facultatif") por cualquier persona en los debates a celebrar en ambas Cámaras del Parlamento de Canadá y en el Legislativo de Quebec. De igual forma la publicación de las Leyes emanadas en el Parlamento de Canadá y en el Legislativo quebequés será bilingüe — no en ningún otro legislativo provincial $^{30}$, sólo en el quebequés, asimetría de iure—. El sistema judicial también

28 WOEHRLING, J., "Cuestiones sobre la reforma del Senado en Canadá", en R.V.A.P. n. 35 (II), 1993, págs. 125-136; ALBERTÍ, E., "El Senado canadiense", en VV.AA., Ante el futuro del Senado, Generalitat de Catalunya, Institut d’Estudis Autonòmics, Barcelona, 1996, págs. 226-227.

29 La designación formal es realizada por el Gobernador General en nombre de la Reina (art. 24 LC). En consecuencia la designación a la que aluden los preceptos constitucionales citados alude exclusivamente a la procedencia de los senadores, a respetar por la decisión del Gobernador.

30 Esta tajante afirmación se predica en exclusiva de la inicial redacción de la Ley Constitucional de 1867, puesto que un artículo similar fue aprobado para Manitoba en el art. 23 de su Constitución, Manitoba Act, 1870, confirmado por la Constitution Act de 1781 y reforzado en su rango constitucional por el art. 52 LC 1982. 
será objeto de aplicación de esa convivencia y posibilidad de uso alternativo del francés y del inglés. Es importante delimitar el ámbito de esta aplicación: los poderes legislativo y judicial federales y los respectivos poderes existentes en Quebec. A partir de ahí se podrán entender las críticas a la parquedad de tal regulación: por un lado, no extender su aplicación a otras provincias donde conviven minorías lingüísticas semejantes; por otro, no ampliar al poder ejecutivo tales disposiciones; finalmente, no consolidar la cooficialidad lingüística. Empero, nuestra opinión es favorable a considerar dicha redacción como una asimetría de iure, limitada o de mínimos, pero al fin y al cabo asimetría. Su justificación redunda en que cumple con la exigencia de trasladar a la norma la excepcionalidad, en este caso lingüística, de un territorio y de sus habitantes ${ }^{31}$.

La segunda faceta en la que reparábamos, la religiosa, tiene una enorme importancia en el momento de la redacción constitucional. El art. 93.2 no sólo trata de proteger la impronta religiosa de un sistema educativo. En el contexto de la Constitución de 1867 hablar de Quebec es hablar de religión católica y hablar del resto de Canadá es hablar de religión protestante. La titularidad en materia de educación corresponde a los Legislativos provinciales (art. 93 LC 1867) y por lo tanto reflejar esta asimetría, en el específico caso de Quebec, contribuye a subrayar su singularidad. En su apoyo, el mismo art. 93 en su epígrafe cuarto señala que el incumplimiento de lo en él dispuesto será objeto, mediante "remedial Laws", de la intervención del Legislativo central, reforzando su contenido. Es, por tanto, otra asimetría de iure $e^{32}$.

En resumidas cuentas, desde la literalidad de la Constitución se preludian las tensiones entre simetría y asimetría que marcarán con más intensidad las etapas futuras. La Constitución de 1867 apuesta por una forma asimétrica, sobre la que se construye y que implícitamente reconoce.

\section{I.4. Federalismo Renovado: Trudeau y la ley constitucional de 1982}

Tras un período de gran inestabilidad provocado por los elementos separatistas francófonos, que llegaría incluso a culminar en la creación de un grupo terrorista, el Front de Liberation du Québec (FLQ), el triunfo del Parti Québécois (fundado en 1968) en las elecciones de la Provincia de Quebec de 1976 marcó un nuevo hito, referenciable a partir de su slogan "Soberaníaasociación". La inmediata consecuencia fue la de imprimir el sello de "urgente" a la búsqueda de una solución al problema de las relaciones de Quebec con el resto de Canadá33.

31 Cfr. MILNE, D., "Equality or Asymmetry: Why Choose», en WATTS, R. L., y BROWN, D. M (eds.), Options for a New Canada, University of Toronto Press, Toronto,1991, pág. 289.

32 En el año 1997 el art. 93 fue objeto de una enmienda - vid infra. nota 6-, en virtud de la cual se procedió a añadir un nuevo art. 93A, que dispone: "Los parágrafos (1) a (4) del artículo 93 no se aplicarán a Quebec".

33 Uno de los primeros ítems será un Proyecto de Ley sobre la reforma Constitucional, que iniciaría su tramitación en el Parlamento Federal en el mes de junio de 1978. Desde su Preámbu- 
Formalmente, la el resultado será la elaboración de un documento conocido como informe Pepin-Robarts, (Task Force on Canadian Unity) ${ }^{34}$, elaborado en 1979. El contexto en el que se introduce es el de la reincidente aporía de "igualdad $v s$. status diferenciado". Si en un primer lugar se establece que "la definitiva característica de cualquier sistema federal es la igualdad de status bajo la Constitución de los dos órdenes de gobierno, central y provincial". De inmediato se procederá a reconocer que "la posición única de Quebec donde lo que es una minoría lingüística dentro del conjunto del país constituye la mayoría, ha llevado a planteamientos según los cuales a esa provincia debería garantizársele una serie de poderes sobre concretas materias denegados a otras provincias ${ }^{35}$.

La solución propuesta es doble. Por un lado simbólica, procediendo a la sustitución de la expresión "status especial" por la de "status diferenciado", que obvia la connotación peyorativa de la primera. Por otro práctica, la búsqueda de una solución que proteja y desarrolle ese carácter diferenciado sin generar la ruptura de Canadá.

En este contexto y con estos precedentes dogmáticamente aperturistas y conciliadores $^{36}$ se celebró el 20 de Mayo de 1980 el referéndum en Quebec, en el que el Parti Québécois conminó a los quebequeses a pronunciarse sobre su proyecto de "soberanía-asociación". Empero, el resultado negativo de ese referéndum - el 60\% de los electores votó negativamente- no fue del todo vano. El Primer Ministro TRUDEAU prometió la búsqueda de una tercera vía entre el status-quo y la propuesta de "soberanía-asociación", bajo la fórmula de un federalismo renovado ( renewed federalism") ${ }^{37}$.

Tras un intenso período de negociaciones el resultado se plasmó en la aprobación de la Constitution Act de 1982. Sus dos pilares esenciales fueron el establecimiento de un procedimiento para la reforma constitucional y la adopción de una Carta de Derechos y Libertades.

lo se afrontaba el reconocimiento de la dualidad anglófona-francófona que ha marcado la historia canadiense. Le Projet de Loi sur la réforme constitutionnelle, Ottawa, Gouvernement du Canada, 1978.

34 Task Force on Canadian Unity, A future together: Observations and Recommendations, Minister of Supply and Services Canada, Ottawa, 1979. Por mandato del gobierno federal se creó en 1977 un grupo de asesores que integraron el "Task Force on Canadian Unity". Su función era la de recoger las percepciones de los canadienses relativas a la situación del país. Conscientes de que "el principal, pero no el único, reto viene de Quebec" (pág. 3), recorrieron buena parte de la vasta superficie canadiense para realizar este informe. El punto de partida de esta urgente reflexión era el triunfo del Partido Quebequés en el Gobierno de Quebec el 15 de noviembre de 1976 y la necesidad, por tanto, de afrontar una de sus propuestas, la potencial secesión de Quebec.

35 Ibidem, idem.

36 Junto al informe Pepin-Robarts hay que añadir el conocido como "Beige Paper", elaborado por el Partido Liberal de Quebec en 1980, en el que se adoptaba una postura similar favorable al incremento de los poderes de Quebec sin quebrar la unidad canadiense. The Constitutional Committee of the Quebec Liberal Party, A New Canadian Federation, The Quebec Liberal Party, Montreal, 1980, págs. 12-13.

37 FOURNIER, P., A Meech Lake post-Mortem. Is Quebec sovereignty inevitable?, McGillQueen’s University Press, Toronto, 1991, pág. 7. 
La nueva fórmula de reforma constitucional trataba por igual a todas las Provincias. El procedimiento ordinario de reforma de la Constitución implicaba su aprobación por las dos Cámaras del Parlamento y por siete provincias, siempre y cuando representasen el 50\% de la población federal (art. 38.1.a y b LC 1982). Este último requisito, no obstante, reitera la exigencia de que ora Quebec, ora Ontario apoyen el procedimiento de reforma. Por su parte, la Carta de Derechos y Libertades, principal proyecto de TRUDEAU, subrayaba la igualdad de derechos de todos los ciudadanos canadienses (art. 15 LC 1982) e incidía en la promoción de iguales oportunidades para todos ellos

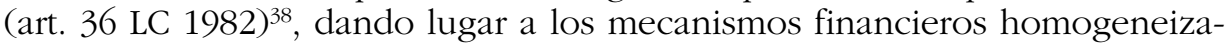
dores de "perecuación" 39 .

Las consecuencias de la aplicación de la Carta Canadiense sobre el federalismo han sido marcadamente centralizadoras. Empero, como señala WOEHRLING, el efecto boomerang de todas estas opciones nunca puede ser ignorado en un contexto federal ${ }^{40}$.

Así, el rechazo de Quebec a la reforma constitucional de 1982 significaba que los problemas fundamentales seguían sobre el tapete negociador. La lle-

38 PELlETIER, B., La Modification constitutionnelle au Canada, Carswell, Toronto, 1996, págs. 215-243; TREMBLEY, A., La réforme de la Constitution au Canada, Les Éditions Thémis, Montreal, 1995, págs. 46-75. Ambos Tratados glosan los sucesivos proyectos de fórmulas de repatriación: la fórmula Fulton de 1961, Fulton-Favreau de 1964, la Charte de Victoria de 1971 y las proposiciones no gubernamentales y las gubernamentales, que cuajarían en la definitiva reforma de 1982.

39 La perecuación o ecualización (equalization) es un mecanismo redistributivo cuyo origen, en el contexto canadiense, puede datarse en 1957. Su finalidad radica en tratar de conseguir, mediante la redistribución de recursos, unos estándares de vida comunes en el conjunto de la federación. Una descripción simplificadora de su funcionamiento, sobre el que precisamente la crítica principal es la de ser extremada y confusamente complejo, radica en los siguientes puntos. En primer lugar, se procede a baremar la capacidad fiscal de una provincia con respecto a un referente nacional, fruto de promediar la capacidad financiera de un número determinado de provincias. En segundo término, las provincias que han sido utilizadas como referentes han variado: en 1957, Ontario y la Columbia Británica, que eran en ese momento las dos provincias más ricas; en los sesenta se procedió a incluir a las diez provincias; en los setenta, la inclusión de Alberta, rica en petróleo, condujo a elevar tanto ese referente que incluso Ontario habría tenido que recibir fondos de ecualización; en 1982, se eliminó a Alberta y a las provincias más pobres del bloque provincial que debería ser tomado como referente para el cálculo; en la actualidad ese estándar nacional está basado en un cálculo sobre la capacidad fiscal de cinco provincias de renta media que son Columbia Británica, Ontario, Saskatchewan, Manitota y Québec. En tercer lugar, los referentes utilizados han variado, desde tres originariamente (Impuesto de Sociedades, Impuesto sobre la Renta personal, Impuesto de sucesiones), hasta treinta y tres en la actualidad. Finalmente, las críticas al sistema vienen de quienes se consideran como "pagadores netos" del mismo, Alberta, de quienes estiman que genera dependencia y de quienes reclaman su incremento.

40 "Hay un acuerdo general para sostener que, efectivamente, la Carta canadiense ha creado en los canadienses anglófonos una nueva conciencia cívica fundada en la reivindicación de derechos y la expresión de identidades que se articulan a nivel nacional más que a nivel regional o provincial. Contrariamente, la Carta canadiense ha agravado las divisiones y el antagonismo entre Quebec y el resto de Canadá". WOEHRLING, J., "Las Consecuencias de la aplicación de la Carta de Derechos y Libertades en la vida política y democrática y en el federalismo en Canadá", en Derechos y libertades en Canadá. MITJANS, E. (Ed.), Atelier, Barcelona, 2005, pág.112. 
gada al poder en 1984 del Partido Progresista-Conservador, liderado por Brian Mulroney, acompañado, en 1985, por el retorno del Partido Liberal de Quebec al gobierno de esta provincia contribuyeron decisivamente a la creación de un nuevo clima proclive a la adopción de acuerdos en sede política. El primero de los resultados de las negociaciones entabladas fue el Acuerdo del Lago Meech, consensuado por el Primer Ministro Federal y por los diez premiers provinciales ${ }^{41}$.

El contenido de este acuerdo lo podemos circunscribir a dos aspectos fundamentales. El primero de ellos incorpora una enorme carga simbólica y de marketing político: el explícito reconocimiento de la posición asimétrica de Quebec dentro de Canadá se materializó en la inclusión de la descripción de Quebec como sociedad diferenciada "distinct society/societé distincte». El segundo elemento revelador del contenido del Acuerdo fue la incorporación "simétrica" de específicos elementos concernientes a Quebec, esto es de elementos teóricamente asimétricos. La finalidad de esta paradójica técnica, que se reitera en las diferentes etapas de la evolución del sistema federal canadiense, es sencillamente lograr su aceptación por parte del resto de Canadá. En esta línea, se incluía la extensión del veto provincial a las propuestas de reforma constitucional.

Las enormes expectativas depositadas en este Acuerdo ${ }^{42}$ chocaron frontalmente con su tortuoso proceso de ratificación. De conformidad con el art. 39.2 LC 1982 se disponía de tres años para afrontar tal ratificación, pues su contenido pretendía la reforma de la Constitución (1987-1990). En ese impasse temporal, tres de las diez Provincias inicialmente signatarias cambiaron de equipo gubernamental. Estos cambios se tradujeron en demandas ad hoc para la ratificación del Acuerdo, que tenían como denominador común el rechazo de la consideración de Quebec como una "sociedad diferenciada". Puesto que en el contenido del Acuerdo se incluía una propuesta de revisión al procedimiento de reforma de la Constitución, era exigible que esta propuesta fuese apoyada por unanimidad (art. 41 LC 1982). Cuando el 23 de junio de 1990 el límite de los tres años expiró dos Provincias, Terranova y Manitoba, no habían aún ratificado el Acuerdo. La raíz de su fracaso estuvo,

41 Sobre este Acuerdo vid. BULLAIN, I., "Quebec y el Acuerdo Constitucional de Lac Meech", en R.E.P., n. ${ }^{\circ}$ 69, julio-septiembre 1990, págs. 217-238; WATTS, R. L., y BROWN, D. M., (Edits.), Canada: The State and the Federation 1990, Institute of Intergovernmental Relations, Kingston, 1990, apéndice, págs. 271-289 y WATTS, R. L., "Canadian federalism in the 1990`s: Once more in Question", en Publius, vol. 21, n. ${ }^{\circ}$ 3, summer 1991, págs. 169-190.

42 Inmediatamente después de la firma del Acuerdo del Lago Meech se celebró un acuerdo institucional entre el Presidente del gobierno federal y los diez premiers provinciales, Accord Meech-Langerin, _ por su celebración en el edificio Langerin-, el 3 de junio de 1987, en el que se perseguía la consolidación constitucional del contenido del Acuerdo del Lago Meech. En él se establecía una regla interpretativa que modificaba el contenido del art. 2 LC 1867, en el sentido de reconocer a Quebec como una sociedad diferenciada (art. 2.1.b) y de asignar al legislativo y al gobierno de Quebec el "rôle" de promover dicho carácter diferenciado (art. 2.3). Cfr. MORIN, J. Y., y WOEHRLING, J., Les constitutions du Canada et du Québec du Régime Français à nous jours, Éditions Thémis, Montreal, 1992, págs. 897-910. 
nuevamente, en el rechazo frontal a un tratamiento diferenciado de Quebec, independientemente de la fórmula para ello adoptada.

La resaca del fracaso de los Acuerdos del Lago Meech incentivó una nueva tentativa de solución de la dualidad canadiense que se plasmaría en una serie de propuestas del Gobierno Federal formuladas por un "Comité sobre la Constitución y las negociaciones constitucionales". Entre sus veintiocho propuestas destaca la necesidad de ampliar el bilateralismo, con el que hasta el momento se enfocaba el problema de "Quebec \& ROC", optando por una "Mesa Redonda" en la que se incluyeran las posturas de todas las provincias desde un primer momento y no sólo en el ítem final de los acuerdos.

La estela de estas propuestas se concentró en una incentivación del debate público sobre la situación de "cuasi-cohabitación" entre Quebec y el resto de Canadá. Esta discusión, desarrollada en diferentes foros, la podríamos periodificar en torno a tres momentos ${ }^{43}$ : el primero, que abarcaría desde octubre de 1991 a finales de febrero de 1992 y que se concretó en el debate sostenido en el Comité Parlamentario Conjunto Beaudoin-Dobbie. Un segundo período, el más informal, pero probablemente el más fructífero consistió en la traslación a los medios de comunicación de estos grandes problemas constitucionales, mediante una serie de seis debates y conferencias televisados que se desarrollaron entre enero y marzo de 1992. Un tercer momento (desde marzo a agosto de 1992) se entregaría a desarrollar una serie de complejas negociaciones interministeriales, dando cabida en estos foros informales a representantes del Gobierno federal, de las Provincias, de los Territorios y de las cuatro principales asociaciones de grupos aborígenes. El resultado de esas negociaciones fue una serie de compromisos que se consignaron en un acuerdo consensuado que se firmaría el 28 de agosto de 1992 en Charlottetown.

Charlottetown representa una apuesta definitiva por la ampliación del espectro de los problemas a debatir. El planteamiento era básicamente simétrico ${ }^{44}$, pero permitiendo elementos de asimetría en su aplicación y en su configuración ${ }^{45}$. Sin minorar, al igual que sus precedentes, la atención prestada a Quebec se incluyeron en la agenda otras cuestiones cuya finalidad era básicamente salvar la aprobación del Acuerdo ${ }^{46}$, algo que nueva-

43 Vid. el Prefacio al texto definitivo del Acuerdo de Charlottetown. Consensus Report on the Constitution, Charlottetown, August 28, 1992: final Text, Minister of Supply and Services Canada, Ottawa, 1992, págs. i-ii.

44 Reforma del Senado (art. 8) y realización de pagos y transferencias igualitarias a las Provincias (arts. 4 y 5).

45 La propuesta de reforma del art. 1 LC 1867 interpretando "la Constitución de Canadá, incluyendo la Carta canadiense de Derechos y Libertades, de forma consistente" con una serie de ocho propuestas entre las que cabría destacar: "C. Quebec constituye dentro de Canadá una sociedad diferenciada, que incluye una mayoría de franco-parlantes, una única cultura y una tradición de derecho civil".

46 La expresa consignación de la "igualdad de todas las provincias" (art. 1.2.1.d.). Sobre el rechazo del Acuerdo vid. BRUN, H. y TREMBLAY, G., Droit Constitutionnel, 3.. ${ }^{a}$ edic., Les éditions Yvon Blais, Cowansville, 1997, pág. 126; WHITAKER, R., "The dog that never barked: who killed asymmetrical federalism?", en MCROBERTS, K. y MONAHAN, P.J. (Eds.), The Charlottetown 
mente no se conseguiría al ser rechazado en Quebec y en las provincias del Oeste.

Tres años después la singularidad quebequesa volvía a copar protagonismo en el sistema democrático canadiense al celebrarse un referéndum el 30 de octubre de 1995, sustentado por los líderes independentistas del Partido Quebequés (Jacques Parizeau), del Bloque Quebequés (Loucien Bouchard) y Acción Democrática (Mario Dumont). La propuesta "confederal" que se debatía, al reivindicarse la soberanía de Quebec, implicaba su secesión del Estado federal canadiense con el que, no obstante, se firmaría un pacto de asociación política y fundamentalmente económica. Nuevamente, la arriesgada propuesta no triunfó ${ }^{47}$. Por un estrecho margen de algo más de un punto — 50,6\% contra 49,4\%—, unos 53.000 votos aproximadamente, Canadá continuó siendo un Estado federal y Quebec uno de sus componentes federados.

El último ítem de este período, esencialmente pactista o de discusión, se podría cifrar en la propuesta del Ministro federal de Asuntos Intergubernamentales, Dion, S., formulada el 3 de diciembre de 1997 en Montreal en virtud de la cual se procedería al "reconocimiento del carácter único de la sociedad quebequesa, compatible con la igualdad de status de las provincias, según el principio por el cual la igualdad no es sinónimo de uniformidad ${ }^{48}$. Esta propuesta se calificaría de formalmente impecable, pero materialmente compleja y de difícil implementación. Este último aserto, es el punto de inflexión en nuestro discurso ¿qué hay más allá de la teoría constitucional? ¿cómo se ha contribuido a desarrollar el federalismo canadiense desde la práctica judicial y política?

\section{IMPLEMENTACIÓN DEL MODELO CONSTITUCIONAL: LA REALIDAD DE LA FEDERACIÓN CANADIENSE}

Cualquier Estado, particularmente uno federal y, en especial, Canadá presenta una interesante desviación en lo que respecta a su diseño formal, esencialmente en un texto constitucional, y su implementación práctica, el funcionamiento real de ese Estado. En Canadá son diferentes agentes quienes han intervenido de manera decisiva para que ese "gap" entre la teoría y la práctica sea tan importante: en primer lugar la práctica judicial, especialmente la reorientación descentralizadora que han ejecutado primero el Privy Council y luego el Tribunal Supremo; segundo, la importancia decisiva de las

Accord, the referendum and the future of Canada, University of Toronto Press, Toronto, 1993, pág. 108.

47 La pregunta formulada a los quebequeses fue: “Acepta usted que Quebec sea soberano, después de haber realizado una oferta formal a Canadá de una nueva asociación económica y política, dentro del marco de la Ley relativa al futuro de Quebec y del acuerdo firmado el 12 de junio de 1995?".

48 CROISAT, M., "Le féderalisme asymétrique: L'experience canadienne", Revue française de Droit constitutionnel, n. ${ }^{3}$ 37, 1999, pág. 42. 
relaciones intergubernamentales como cauce de flexibilización del sistema y de actualización constante de su funcionamiento; tercero, la manera en cómo se ha gestionado recientemente la presencia de Quebec en el federalismo canadiense y, finalmente, la importante aplicación de los primeros ministros, particularmente del actual, en el diseño del federalismo.

\section{II.1. Federalismo descentralizado: intepretación Judicial Del Federalismo CANADIENSE}

Una de las consecuencias fundamentales de la adopción de una forma territorial de Estado donde la facultad de legislar se reparta entre dos órdenes de poder es la generación de conflictos y la consiguiente necesidad de habilitar un órgano para su resolución. Sin embargo, la existencia del Tribunal Supremo no es coetánea a la creación de la Federación canadiense. La razón estriba en que el Comité Judicial del Consejo Privado en el Reino Unido funcionaba como un tribunal de apelación al que recurrían todas las colonias británicas. Empero, el art. 101 de la British North América Act permitía la creación de un tribunal en Canadá. La continuidad de este precepto se materializó en la creación del Tribunal Supremo ${ }^{49}$ en 1875 (Supreme and Exchequer Courts Act, reformándose en 1985 con la Supreme Court Act) ${ }^{50}$. La designación de los jueces del Tribunal Supremo canadiense corresponde al ejecutivo ${ }^{51}$.

49 La revisión de la validez de la legislación aprobada por los cuerpos legislativos canadienses se sustenta en un argumento basado más en el imperialismo que en el constitucionalismo. Si una ley era contraria a la BNA, ésta tendría que prevalecer dado que era una ley imperial. La Ley de Validez de las Leyes coloniales les confería esa potestad abrogatoria. Desde 1982, esta doctrina cambia, al incluirse la cláusula de supremacía de la Constitución, en la Ley Constitucional de 1982 —art. 52 (1)—, fundamento actual de la revisión judicial en Canadá. Cfr. HOGG, P., Constitutional Law of Canada, ob. cit., pág. 135.

50 El Tribunal Supremo de Canadá estaba compuesto originariamente de seis jueces, de los que dos al menos deberían proceder de Quebec en virtud del mandato de la ley de 1875. En 1927 se agregaría un séptimo juez, pasando en 1949 a ser nueve jueces de los cuales tres habrían de proceder de Quebec. Precisamente, desde ese año se ha impuesto una representación regional en la composición del Tribunal Supremo, merced a la cual a los tres jueces procedentes de Quebec por mandato legal, se agregan tres procedentes de Ontario - fundamentándose esa decisión en que Ontario debería tener el mismo número de jueces que Quebec-, dos de las provincias occidentales y uno de las provincias atlánticas. El presidente del tribunal rota de modo alternativo entre un angloparlante y un francófono. Desde el 7 de enero de 2000, una mujer, Beverley McLachlin, procedente de Columbia Británica, es la presidenta del tribunal.

51 Art. 26. Ley del Tribunal Supremo de 1985. La designación del presidente del tribunal se atribuye al Primer Ministro, mientras que el resto de jueces parecen ser propuestos por el Ministro de Justicia. Es interesante comentar que una de las propuestas del Primer Ministro Harper, en su campaña de 2006, fue la de buscar el apoyo popular de cualquier designación a través de un comité parlamentario. Coherentemente con esa promesa electoral, la designación del juez Rothstein, implicó una audiencia pública en el parlamento, previa a su designación oficial, el 1 de marzo de 2006. El 22 de diciembre de 2008 se designaría otro juez, Thomas Albert Cromwell. El periplo de su designación fue enormemente influenciado por el difícil equilibrio político sobre 
El papel desempeñado por el Tribunal Supremo y por su antecesor, el Comité Judicial del Consejo Privado, en el diseño del federalismo canadiense es el de optar por un referente de federalismo descentralizado, por contraposición al identificado en la Constitución ${ }^{52}$.

En la relación competencial que aparece en la Ley constitucional de 1867, tres son los ámbitos materiales que han sido sustancialmente influenciados por la interpretación judicial: primero, el preámbulo al artículo 91, la mencionada "cláusula POGG" — peace, order and good government-, que garantiza al parlamento federal la potestad para aprobar leyes para el bienestar general del país; segundo, la competencia general de las provincias sobre propiedad y derechos civiles (art. 92.13) y, finalmente, la competencia federal sobre reglamentación del tráfico y el comercio (art. 91.2).

En lo concerniente a la interpretación de la cláusula POGG, inicialmente, el Comité Judicial del Consejo Privado procedería a su conversión en un tercer ámbito competencial, a agregar a los de titularidad federal y provincial, respectivamente arts. 91 y 92 BNA, concibiéndose como una garantía extra otorgada al Parlamento federal para usarla en circunstancias extraordinarias, esto es en situaciones de emergencia nacional. El recurso a la cláusula POGG sólo se habilitaba en los casos en que pudiera probarse que, para evitar una crisis pan-estatal, la autonomía provincial tenía que limitarse. La primera oportunidad para definir su alcance tuvo lugar en 1922 (Re: Board of Commerce Act) en la que los Lores no apoyaron los amplios poderes incorporados en la legislación estatal coincidente con el comienzo de la I Guerra Mundial en la que se prohibían los monopolios y la especulación. Únicamente, circunstancias como la guerra o el hambre podrían, sensu contrario, justificar el recurso a dicha cláusula POGG ${ }^{53}$. Tan sólo un año después, en Fort Frances Pulp Co. V. Manitoba Free Press, el Consejo paradójicamente no dudó en

el que se sustenta el gobierno conservador. Cuando el presidente Harper en el verano de 2008 planteó la necesidad de suplir la vacancia generada por la renuncia del juez Bastarache, anunció simultáneamente que se realizaría una comparecencia legislativa como con el juez Rothstein, sin embargo la premura de la convocatoria electoral aceleró el anuncio de la persona designada y el compromiso de esa comparecencia. Los apretados resultados de las elecciones de octubre, generaron una prórroga del parlamento y la consiguiente no convocatoria del comité al que debería de haber comparecido el nuevo juez. El 22 de diciembre se procedió a ese nombramiento, acabando con los ocho meses de situación de vacancia en el Tribunal Supremo. Lo que si se produjo fue una consulta al líder de la oposición, del que se obtuvo su plácet, y una promesa de comparecencia y control por un comité parlamentario del nombramiento de Cromwell, lógicamente ex post. Con Cromwell se restaura el equilibrio territorial de los jueces, con uno procedente del Atlántico. La prensa se hizo eco de este paradójico nombramiento y de las dificultades de Harper para acometer sus compromisos políticos. "Hurry, without hearing", Globe and Mail, 23 de diciembre de 2008 y ASPER, D., "Harper chooses the lesser evil in making appointments", en National Post, 27 de diciembre de 2008.

52 Como recuerda Hogg, eso llevaría a que Forsey describiera a los miembros del Comité Judicial del Consejo Privado como los "malvados padrastros de la confederación". HOGG, P., Constitutional Law of Canada, ob. cit., pág. 128.

53 BAKAN, J., Canadian Constitutional Law, Montgomery Publication, Toronto, 3. ${ }^{\circ}$ ed., 2003 , pág. 127. 
sustentar la justificación del control del precio del papel por el gobierno en circunstancias de guerra, aun cuando la guerra ya hubiere terminado. El Comité Judicial del Consejo Privado también avalaría el recurso a la cláusula POGG en otros supuestos distintos a los de situaciones de emergencias. Así, en Re: Regulation and Control of Aeronautics of Canada (1932), el Comité avaló la constitucionalidad de la legislación federal en el control del tráfico aéreo, la concesión de licencias a pilotos y la seguridad aérea, a partir de lo regulado en el art. 132 BNA, conocido como la cláusula de los Tratados del Imperio, en el que se establece que «el Parlamento y el Gobierno de Canadá tendrán las competencias necesarias para cumplir las obligaciones de Canadá o algunas de sus provincias para con países extranjeros, como parte del Imperio Británico, originadas en tratados firmados entre este último y dichos países». Igualmente, el Comité alivió la drástica exigencia de emergencia nacional, sustentando el apoyo de la cláusula POGG en un fundamento más sutil, como el del "interés nacional", en el caso de Attorney General of Ontario v. Canada Temperance Federation (1946), en el que se evaluaba la constitucionalidad de la ley federal reguladora de la abstinencia fechada en 1927 , en la que se permitía participar a los municipios - la versión canadiense de la Ley seca norteamericana, plasmada en la enmienda XVIII a su Constitución- No obstante, la concepción restrictiva de la cláusula POGG se manifestó con claridad meridiana en la negativa del Comité Judicial del Consejo Privado de asumir que la legislación federal conocida como "Bennet New Deal", aprobada para ayudar a los canadienses a afrontar las condiciones sociales y económicas de la gran depresión, se justificase por motivos de emergencia, declarándose consecuentemente ultra vires ${ }^{54}$.

La verificación de la impronta descentralizadora con la que se desarrolló la revisión judicial se hace más explícita en la interpretación de las competencias provinciales sobre propiedad y derechos civiles, normalmente a costa de la competencia federal de reglamentación del tráfico y el comercio. En Citizens Insurance Co. V. Parsons (1881), el Comité Judicial consideró que la regulación del seguro de incendios no recaía dentro de la competencia federal en materia de tráfico y comercio, sino en el abanico competencial provincial, sosteniendo que la competencia federal se refería fundamentalmente a la regulación del comercio con otras naciones y al comercio interprovincial. Esa posición se ratificó en 1916 al sostener que el poder federal en materia comercial era una competencia auxiliar, incapaz de servir por sí misma como una fuente primaria de capacidad legislativa (Attorney General of Canada $v$. Attorney General of Alberta).

54 Los casos referidos como "New Deal" incluyen Labour Conventions Reference, A.C., 327 (1937), the Employment and Social Insurance Reference, A. C., 355 (1937) y el National Products Marketing Act Reference, A. C., 377(1937). Es de destacar el rechazo al argumento del Gobierno federal de que el seguro de desempleo fuese una materia de "interés nacional", instando una reforma constitucional para su consideración como tal, algo que se produciría en 1940, dando lugar al vigente art. 91.2A. 
A partir de 1949, cuando el Tribunal Supremo sustituyó al Comité Judicial del Consejo Privado, podemos evidenciar ciertos cambios en el sentido de la revisión judicial. Tres son los referentes de ese nuevo talante: la potenciación del interés nacional, vinculado a la cláusula POGG, la asunción de la constitucionalidad de un modelo de federalismo cooperativo donde la "delegación" cobra un papel decisivo y la interpretación generosa de títulos competenciales sustantivos del orden federal como derecho penal o el seguro de desempleo.

La expansión de la noción de interés nacional, avanzada en el Canada Temperance case, se confirmó con la adición a la lista de materias bajo control federal merced a la cláusula POGG de las siguientes: aeronáutica (Johannesson v. West St. Paul, 1952), energía atómica (Pronto Uranium Mines, Ltd. V. O.L.R.B., 1956) y recursos naturales marinos (Offshore Mineral Rigths of B.C., 1967). En los noventa, en varios litigios relativos a legislación medioambiental, el tribunal tuvo de nuevo la oportunidad de ampliar la doctrina del interés nacional, mediante lo que se ha conocido como "test de incapacidad provincial", en referencia a las situaciones en las que la incapacidad de una provincia para actuar en algún área particular podría tener efectos adversos sobre otras provincias (R.v. Crown Zellerbach Canada Ltd., 1988).

Pese a las reticencias iniciales a aceptar formatos de federalismo cooperativo (Attorney General of Nova Scotia v. Attorney General of Canada, 1951), la delegación desde el Parlamento federal a otras instancias sin la transmisión de la titularidad de la potestad legislativa se aceptó como un mecanismo agilizador (P.E.I. Potato Marketing Board v. H. B. Willis, 1952). Muy recientemente, el Tribunal ha vuelto a pronunciarse en materia de delegación, en este caso tributaria, admitiendo su constitucionalidad sólo en aquellos supuestos en que «la legislación establece expresamente y de modo no ambiguo tal delegación," 55 .

El Tribunal ha incidido en cuestiones muy polémicas, reforzando el poder federal, en materia de derecho penal -incluyendo en ese título el almacenaje de productos tóxicos (R. v. Hydro-Québec, 1997) o un registro nacional de armas de fuego (Reference Re: Firearms Act Canada, 1998)—. Finalmente, en un contexto de crisis el Tribunal Supremo no ha titubeado al sostener la necesidad de una interpretación "generosa" sobre la competencia federal en materia de seguro de desempleo (Confédération des syndicats nationaux v. Canada (Attorney General), 2008).

La percepción global de cómo se afronta la revisión judicial del federalismo canadiense es que su voluntad estriba en buscar un equilibrio, algo que logra instando la aproximación de la percepción técnico jurídica del federalismo a su real funcionamiento, aspecto en el que cobran un protagonismo esencial las relaciones intergubernamentales.

55 Confédération des syndicats nationaux v. Canada (Attorney General), 2008 SCC 68, 11 de diciembre de 2008. F.J. 87. 


\section{II.2. Federalismo CoOperativo: Del Federalismo EJECUTIVO AL FEDERAlismo LEGISLATIVO EN LAS RELACIONES INTERGUBERNAMENTALES}

El carácter inevitable ${ }^{56}$ del solapamiento entre la legislación provincial y federal ha instado a la búsqueda de alternativas pragmáticas que impidan el bloqueo del Estado. Dado que la Constitución no puede reformarse paralelamente al ritmo trepidante que la realidad demanda, la responsabilidad para asegurar el funcionamiento efectivo del sistema federal recae en gran medida en las relaciones intergubernamentales.

Entre las formaciones del federalismo canadiense, la que en el momento actual pueda tener más importancia en el logro de diferentes resultados políticos y en el diseño de las propias relaciones intergubernamentales es el llamado federalismo ejecutivo. El dominio del ejecutivo significa que la mayoría de la interacción del sistema federal canadiense tiene lugar entre los ejecutivos, tanto a nivel político como a nivel funcionarial. Así, el federalismo ejecutivo trabaja en dos direcciones razonablemente distintas: el día a día, donde la carga de las relaciones intergubernamentales recae en el nivel funcionarial y la forma que nos resulta más fácil de asociar al federalismo ejecutivo, la que funciona en la cumbre protagonizada por ministros y primeros ministros provinciales y el federal. Entre los resultados más señeros de ese federalismo ejecutivo podemos citar el Plan de Pensiones de Canadá, en los años 60; el Programa Nacional de Energía, a primeros de los 80, del que resultaría un precio interior para Canadá del petróleo y el gas natural inferior al internacional; el Acuerdo sobre Comercio Interno (AIT) cuya finalidad era la eliminación de fronteras al comercio y a la movilidad económica interprovincial - 1994- o el principal punto de referencia de las Relaciones Intergubernamentales, post-Charlottetown, el SUFA, el Acuerdo para establecer un marco unitario en la prestación de servicios sociales en Canadá, firmado en 199957. Entre quienes han impreso un sello personal al desarrollo de estas relaciones intergubernamentales, se ha de citar a Frank McKenna, durante largo tiempo premier de Nuevo Brunswick (1987-1997), quien destacaría por el talento y la astucia en la conducción de las relaciones intergubernamentales. Más recientemente, los premiers Danny Williams de Terranova y Labrador y John Hamm de Nueva Escocia ${ }^{58}$, tras una larga batalla con Ottawa sobre ecualización y sobre la recuperación de los derechos de las energías producidas en el mar, tuvieron un sonado éxito en su batalla negociadora con el gobierno de Martin ${ }^{59}$.

56 Así se pronuncia el Tribunal Supremo en Chatterjee vs. Ontario, 2009 SCC 19 (17 de abril de 2009), F.J. 32.

57 BAIER, G., "The courts, the division of powers and dispute resolution" en BAKVIS, H., y SKOGSTAD, G., Canadian federalism. Performance, effectiveness and legitimacy, Oxford University Press, Ontario, 2008, pág. 31.

58 Las elecciones de 9 de junio de 2009 desplazaron al partido conservador, desde 2006 liderado por Rodney MacDonald, otorgando la mayoría al prometedor NDP de Darrell Dexter.

59 Uno de los factores de peso en el desarrollo de estas relaciones intergubernamentales es cómo se gestiona la presencia de los medios de comunicación en los mismos y el uso que se les 
Aun cuando, el federalismo ejecutivo aparece fuertemente arraigado en la cultura política federal canadiense hay que hacerse eco de una tenue revisión del mismo, de la mano del denominado federalismo legislativo, merced al cual las asambleas legislativas desarrollarían un papel más activo en el ámbito de las relaciones intergubernamentales, apostando por una reforma de los legislativos, por una minoración de la disciplina de partido y por un refuerzo del papel de los comités legislativos, junto a grupos de expertos, en la revisión de los acuerdos ${ }^{60}$. La ratificación de esta prospectiva la hallamos en la propia jurisprudencia del Tribunal Supremo desde donde se sostuvo que el parlamento y el principio de soberanía parlamentaria en el que se sustenta es el responsable del diseño de los acuerdos intergubernamentales, de modo que aunque el primer ministro adopte un compromiso con las provincias y en ellas se genere una "expectativa legítima" sobre su contenido, sólo el parlamento y no el ejecutivo tiene la autoridad para respaldar su contenido (Reference Re. Canada Assistance Plan (B.C.) 1991, de 15 de agosto, FJ. 42).

\section{II.3. FEDERALISMO SEPARATISTA: LAS TENSIONES TERRITORIALES Y EL FANTASMA DE LA SECESIÓN}

La expresión "federalismo separatista" haría referencia a una modalidad extrema de "federalismo dual" caracterizada por la existencia de un máximo distanciamiento entre uno o varios estados miembros y la federación ${ }^{61}$. El máximo distanciamiento entre Quebec y Ottawa ha tenido en la última década tres iconos esenciales: el dictamen del Tribunal Supremo de Canadá sobre la secesión de Quebec de 20 de agosto de 1998; la Ley federal de la Claridad y la Ley quebequesa sobre el ejercicio de los Derechos Fundamentales y Prerrogativas del Pueblo Quebequés y del Estado de Quebec

En lo que concierne al dictamen, de carácter consultivo, sobre la secesión de Quebec resuelto por el Tribunal Supremo Canadiense el 20 de agosto de $1998^{62}$ proponemos concentrar su análisis en los siguientes aspectos:

confiere. En ese contexto Danny Williams, premier de Terranova y Labrador, es bien conocido por su habilidad para usar los últimos en sus batallas contra Ottawa: poniendo anuncios en los que pide a "Steve" —en alusión al presidente Stephen Harper — ser más justo con Terranova y Labrador; reprendiendo al primer ministro en sus intervenciones públicas; abandonando las reuniones de primeros ministros e, incluso, arriando la bandera canadiense o poniéndola a media hasta en los edificios del gobierno. BAKVIS, H., BAIER, G. y BROWN, D., Contested federalism. Certainty and ambiguity in the Canadian federation, ob. cit., pág. 100.

60 Ibídem, pág. 256.

61 BASSANI, L.M., STEWART, W. y VITALE, A., I concetti del federalismo, ob.cit., pág. 395.

62 Renvoi relatif à la sécession du Québec, in the matter of Section 53 of the Supreme Court Act, R.S.C., 1985, c. 5-26. And in the matter of a Reference by the Governor in Council concerning certain questions relating to the secession of Quebec from Canada, as set out in Order in Council, dated the 30 th of september 1996. (Canada Supreme Courts Reports, part. 2, 1998, vol. 2 [1998]2 S.C.R. 217-441, file n. ${ }^{\circ}$ 25.506). Accesible a través de Internet <http://droit.umontreal.ca/doc/csc-scc/ 
Primero, el esfuerzo del Tribunal Supremo por depurar el proceso jurídico y el político en el debate de la secesión de Québec. Desde la constatación de que la "secesión de una Provincia debe ser considerada, en términos legales, a partir de una necesaria reforma de la Constitución" se está marcando el margen positivo que sanciona un previo debate político, no tasado por el Tribunal, ni sobre el que puede convertirse en "supervisor legal", en el que han de postularse distintas soluciones.

En un segundo lugar, hay que ponderar que el reconocimiento de un silencio constitucional desde la LC 1867 sobre la secesión de una de sus provincias no es óbice para rechazar su potencial materialización, siempre que se afronte desde un marco legal, esto es, se proceda a reformar la Constitución, de forma coherente con los principios básicos de federalismo, democracia, constitucionalidad, Estado de Derecho y respeto a las minorías.

En tercer lugar, el Tribunal no puede soslayar los efectos secundarios de fragmentación o atomización que se "cuelan" en la mayoría de los planteamientos separatistas. Una expresión radical de las diferencias conducentes a reclamar la secesión de un territorio se presentan simultáneamente como despertador de opiniones disidentes en su propio seno, esto es, se azuzarían posiciones igualitarias. $V$. gr. la posición de los pueblos autóctonos personados en el proceso que sostuvieron que, en caso de secesión, los pueblos autóctonos situados en la parte septentrional de Quebec podrían exigir que su territorio continuase formando parte de Canadá.

Una cuarta observación nos lleva a dirigir la mirada hacia el Derecho Internacional y su papel en los procesos internos relativos a la forma de un Estado. El Tribunal Supremo consolidó la postura según la cual el Derecho Internacional no es un corpus jurídico omnicomprensivo bajo cuyo paraguas puedan albergarse todo tipo de pretensiones, incluidas las de secesión. Bien distinto es el papel a jugar por la "Comunidad Internacional». Su participación como juez se reclama en dos supuestos complejos. El primero, ante la hipótesis de "una mayoría política de cada parte que no actuase de acuerdo con los principios constitucionales subrayados" poniendo en riesgo la legitimidad del ejercicio de estos derechos. En román paladino, la ausencia de buena fe

en/rec/html/renvoi.en.html>. La traducción al castellano de las conclusiones alcanzadas por el Tribunal Supremo puede consultarse en Boletín de Documentación, Centro de Estudios Políticos y Constitucionales, Madrid, n. ${ }^{\circ}$ 4, enero-abril 1999, págság. 3-23. Entre los diferentes comentarios que la doctrina dedicó al análisis de tal sentencia se ha de destacar ab initio, por la incuestionable especialización de su autor en esta materia, el realizado por José WOEHRLING, "La Cour suprême du Canada et la sécession du Québec", en Revue française de Droit Constitutionnel, n. ${ }^{3}$ 37, 1999, págs. 3-27. En la doctrina española, podemos referenciar los siguientes: Cfr. RUIZ ROBLEDO, A. y CHACÓN PIQUERAS, C., "El Dictamen del Tribunal Supremo del Canadá sobre el derecho a la secesión de Quebec", en Cuadernos Constitucionales de la Cátedra Fadrique Furió Ceriol, n. ${ }^{\circ} 24$, 1998, págs. 129-180; LÓPEZ AGUILAR, J. F., "Reflexiones a propósito de la reciente sentencia del Tribunal Supremo (TS) de Canadá acerca de la secesión de la provincia de Quebec", en Repertorio Aranzadi del Tribunal Constitucional 1998, vol. IV, Índices y estudios, Editorial Aranzadi, Pamplona,1998, págs. 519-525. 
por cualquiera de las partes conminaría a la Comunidad Internacional a no aceptar el resultado, pro o antisecesionista. Una segunda hipótesis lleva al Tribunal a reparar en la posibilidad de una secesión de facto, cuyo éxito se vincula al de "su reconocimiento por la Comunidad Internacional" ${ }^{63}$. Sobre estas bases, sólo restaría identificar a esa Comunidad Internacional, lo que nos llevaría a la institución por excelencia que la representa, a la Organización de las Naciones Unidas, y a su Asamblea General.

Finalmente, es esa secesión de facto la que copa el interés del Tribunal Supremo, y por qué no reconocerlo, la que ha granjeado las simpatías soberanistas quebequesas. El Tribunal anticipa con meridiana claridad la opción confederal para Canadá, de acuerdo con el principio de efectividad, cuyo límite será la "no retroactividad" de su pronunciamiento.

El estado de la cuestión se materializa en el testigo que el Tribunal Supremo entrega a los "actores políticos" y que se concreta en el supuesto en que «una clara mayoría de quebequeses votase sobre una pregunta clara a favor de la secesión".

La recepción del salomónico ejercicio de ponderación de intereses afrontado por el Tribunal Supremo no se demoraría. Su exposición se reifica en sendas leyes aprobadas, respectivamente, por el Legislativo federal y por la Asamblea Nacional de Quebec. La Ley de la Claridad y la Ley sobre el Ejercicio de los Derechos Fundamentales y Prerrogativas del Pueblo quebequés y del Estado de Quebec.

El 13 de diciembre de 1999 el Ministro de Relaciones Intergubernamentales (Intergovernmental Affairs), Stéphane Dion, presentó ante la Cámara de los Comunes el Proyecto de Ley (Bill) de la Clarity Act, An Act to give effect to the requirement for clarity as set out in the opinion of the Supreme Court of Canada in the Quebec Secession Reference ${ }^{64}$. Esta norma ilustra lo que en la doctrina canadiense ha designado como "legislación contingente" (contingency legislation), término bajo el cual se alude al bloque normativo a establecer por el Legislativo federal encaminado a regular la secesión de cualquier provincia, particularmente de Quebec ${ }^{65}$.

Sobre la base del presupuesto de la exigencia judicial de "una mayoría clara sobre un planteamiento claro" como detonante de las negociaciones encaminadas a la secesión de Quebec y a la ulterior reforma constitucional, la estructura de la Ley de la Claridad destaca por su enorme sencillez: tres artículos, precedidos de un preámbulo donde se asientan las bases de la legislación clarificadora sobre los cauces a seguir en un proceso de separación de una provincia del Estado canadiense.

63 [1998]2 S.C.R. 223.

64 Bill C-20, $2^{\text {nd }}$ Session, 36 ${ }^{\text {th }}$ Parliament, 48 Elizabeth II, 1999. <http://www.parl.gc.ca/36/2/ parlbus/chambuus/house/bills/government/.../C-20_cover-E.htm>.

65 MONAHAN, P. J., "Doing the Rules. An Assesment of the Federal Clarity Act in Light of the Quebec Secession Reference", en C. D. Howe Institute. Commentary, n. ${ }^{135}$, february 2000, pág. 3. La expresión "contingency legislation" fue usada por primera vez por el miembro del Privy Council G. ROBERTSON, a principios de 1996, con el significado que aquí se ha expuesto. 
Los seis apartados del artículo primero de la ley se entregan a ofrecer las pautas fundamentales indicativas de la claridad de la pregunta formulada. Una vez acotado el período en el que se procederá a realizar tal evaluación (los 30 días posteriores a que el gobierno de una provincia presente en su Asamblea legislativa la propuesta secesionista; excepcionalmente cabría su ampliación del mismo con 40 días más en el supuesto que ese período inicial de 30 días coincida en todo o en parte con las elecciones a la Cámara de los Comunes) se afronta la tarea procesal de cómo baremar esa claridad en la pregunta. El apartado cuarto de este primer artículo señala el halo negativo de la misma, esto es, se procede a la identificación de aquellos supuestos que no se consideran indicativos de tal meridiana voluntad secesionista. Son los casos en los que la pregunta del referéndum se proyecte meramente sobre un mandato de negociación sin solicitar una directa expresión de la voluntad de la población de esa provincia sobre su independización del Estado canadiense. Igualmente el legislador estima que una pregunta de un referéndum que incluya en su redacción otras posibilidades añadidas a la separación de Canadá, tales como la celebración de acuerdos políticos o económicos con Canadá, que empañen una directa expresión de la voluntad de la población de esa Provincia sobre su intención de dejar de formar parte de Canadá tampoco constituirán un válido instrumento para verificar esa voluntad y, consecuentemente, para impulsar las ulteriores necesarias negociaciones. A este respecto cabe pensar que una hipotética aplicación retroactiva de esta Ley al referéndum de 1995 celebrado en Quebec, conduciría a rechazar su potencial fuerza impulsora de las negociaciones pro-separatistas, en el caso de un triunfo abrumador del sí, tanto más cuanto que la pregunta que se formulaba incorporaba a su literalidad la conversión de Quebec en un socio político y económico de Canadá, como complemento a la asignación a Quebec del título de soberano, es decir independiente y separado formalmente de Canadá.

El artículo segundo de la Ley se dedica en su integridad a delimitar los parámetros válidos para proceder a identificar la existencia de una clara voluntad separatista por parte de la población de una provincia. Sólo una vez que se haya verificado la claridad y consiguiente validez de la pregunta epicentro del referéndum secesionista, la Cámara de los Comunes procederá a ponderar la existencia de una clara voluntad separatista en dicha provincia. Para ello, la Cámara de los Comunes deberá emitir una Resolución en la que determine si en las circunstancias en que se ha celebrado el referéndum cabe evidenciar la existencia de una clara voluntad por parte de una clara mayoría de la población de esa provincia favorable a dejar de formar parte de Canadá. Los datos objetivos que el legislativo utilizará para formular tal resolución son el número de votos válidos que han configurado la mayoría que virtualmente apoye la separación y el porcentaje de votantes que han participado en la votación con respecto al total de la población con derecho al voto. El punto final de este segundo apartado del artículo segundo completa esos indicadores con un recurso a la ambigüedad difícilmente conciliable con el 
título de la Ley: el tercer criterio o factor a tomar en cuenta por la Cámara de los Comunes se identifica con aquellos "otros aspectos o circunstancias que la Cámara considere relevantes". Los dos párrafos finales de este segundo artículo trasladan la literalidad de las exigencias que la Cámara marcaba en el momento de verificar la claridad de la cuestión formulada, a la verificación del apoyo mayoritario de la población a la opción separatista (sondeo de opiniones entre expertos y políticos y negativa a entrar en negociaciones sin una previa constatación de ese apoyo democrático a la secesión).

El punto y final de la ley viene dado por un tercer artículo cuyos dos apartados se dedican, respectivamente, a señalar el carácter preceptivo de la reforma constitucional para que cualquier provincia pueda separarse de Canadá y a especificar los límites a respetar en cualquier potencial negociación impulsada desde el ejecutivo federal. Así, se prohíbe a cualquiera de los Ministros de la Corona la proposición de una reforma de la Constitución para afrontar la separación de una provincia de Canadá, "a menos que el gobierno de Canadá haya fijado, en las negociaciones previas, los aspectos más relevantes a considerar en ese proceso de segregación, en particular la delimitación entre los ingresos y los gastos que corresponderán a los nuevos sujetos, cualquier cambio en las fronteras de una provincia, los derechos, intereses y peticiones territoriales de los pueblos aborígenes y la protección de los derechos de las minorías".

La aprobación definitiva del texto de esta ley se produjo el 15 de marzo del año 2000, siendo sancionada en nombre de su majestad la Reina Isabel II, el 29 de junio de ese mismo año.

La respuesta inmediata del Gobierno de Quebec a la Clarity Act se produjo tan solo dos días después de la introducción de su Proyecto de Ley en la Cámara de los Comunes. El 15 de diciembre de 1999, se presentó por parte del Ministro quebequés de Asuntos intergubernamentales canadienses, Joseph Facal, ante el Legislativo quebequés un proyecto de Ley que se formalizaría en la Ley relativa al ejercicio de los derechos fundamentales y prerrogativas del pueblo de Quebec y del Estado de Quebec ${ }^{66}$. Su principal afirmación redunda en sostener el derecho del pueblo quebequés "por sí solo" a determinar el régimen político y el status legal de Quebec.

El preámbulo de la Ley relativa al ejercicio de los derechos fundamentales y prerrogativas del pueblo de Quebec y del Estado de Quebec se articula a través de un total de quince considerandos, cuyo denominador común es el estilo, una retórica ampulosa, con el que se enfatizan las singularidades históricas y culturales de Quebec. La fijación de un ambicioso objetivo, "la necesaria reafirmación de los logros colectivos del pueblo de Quebec, las responsabilidades del Estado de Quebec y los derechos y prerrogativas de la Asamblea Nacional con respecto a todos los asuntos que afectan al futuro del pueblo de Quebec", abre la puerta a su materialización a través del articulado de la Ley, cuya estructura es la si-

66 Section 2, Bill 99, 36 ${ }^{\text {th }}$ Legislature, First Session. <http://www.assnat.qc.ca/eng/publications/Projets-loi/publics/99-a099.htm>. 
guiente: Primer capítulo: el pueblo de Québec; Segundo capítulo: el Estado de Québec; Tercer capítulo: el territorio de Québec; Cuarto capítulo: las naciones aborígenes de Québec; Quinto capítulo: disposiciones finales.

En una línea argumental anti-clarity Act, el artículo quinto defiende que "Cuando el pueblo de Quebec sea consultado por medio de un referéndum regulado por la Ley del Referéndum, la opción vencedora es la opción que obtiene la mayoría de votos válidos, equivalente al cincuenta por ciento de los votos válidos más uno". Esta postura contestaría a la disposición del preámbulo de la Ley de la Claridad en la que expresamente se sostenía, siguiendo lo señalado por el Tribunal Supremo en su Resolución, que la democracia significa más que una simple mayoría, por lo que «una clara mayoría a favor de la secesión requeriría crear la obligación de negociar la separación y una cualitativa evaluación se exige para determinar si una clara mayoría está a favor de la separación". Estamos ante la dialéctica de lo cuantitativo frente a lo cualitativo, de lo objetivo frente a lo subjetivo.

El capítulo segundo se dedica a perfilar los rasgos específicos del Estado de Quebec: legítimo (art. 5. $)$, soberano (art. 6. ${ }^{\circ}$ ), con una proyección internacional (art. 7. ${ }^{\circ}$ ) y francófono (art. 8..$^{\circ}$ ). Al afirmar que el "Estado de Quebec deriva su legitimidad de la voluntad del pueblo que habita su territorio" se están defendiendo dos presupuestos. En primer lugar, la ley reitera la convicción en las posibilidades unilaterales de afrontar un proceso de autodeterminación, al margen de lo dispuesto por el Tribunal Supremo, por la Cámara de los Comunes, por el gobierno federal y por las demás provincias que integran el Estado canadiense. En un segundo aspecto, se enfatiza la nota específica de la formación de la federación canadiense, calificable como un federalismo por concentración o un federalismo integrativo, gestado de abajo a arriba por la existencia previa de dos culturas y dos pueblos fundadores.

El punto final a este auténtico manifiesto identitario se contiene en la disposición final, señalándose que "ningún otro parlamento o gobierno puede reducir los poderes, autoridad, soberanía o legitimidad de la Asamblea Nacional, o imponer obligaciones a la voluntad democrática del pueblo de Quebec para determinar su propio futuro".

El 30 de mayo de 2000, un mes después de la aprobación de la Clarity Act por la Cámara de los Comunes, la Asamblea Nacional de Quebec aprobaba este texto cuya sanción se fecha el 13 de diciembre de ese mismo año.

\section{II.4. LA IMPRONTA PRESIDENCIAL EN EL DISEÑO FEDERAL: FEDERALISMO ABIERTO}

Los años siguientes hasta el momento presente han sido testigos de una resaca separatista con un interesante cambio en la composición política del Parlamento canadiense y de la Asamblea Nacional de Quebec ${ }^{67}$. El liderazgo

67 Un dato importante es revisar las composiciones legislativas de Quebec y Canadá en ese período. En lo que respecta a Quebec el Partido Quebequés sería relevado del poder en el año 
minoritario conservador, tras las elecciones celebradas el 23 de enero de 2006 en Canadá, puso punto final a doce años de gobierno liberal, otorgando el poder al actual presidente canadiense Stephen HARPER. La autoinmolación de los liberales fue la clave de esta victoria anticipada por todos los sectores. Para sorpresa de todos y, fundamentalmente, con el ánimo de superar esa comentada posición de gobierno en minoría, los canadienses fueron citados nuevamente a las urnas el 14 de octubre de 2008. Se conseguiría la reelección, pero no la mayoría anhelada ${ }^{68}$.

La impronta presidencial al federalismo se manifestó desde la misma campaña electoral de 2006, colándose entre de los principales elementos de cariz político con que se aspiraba al gobierno - promulgación de una ley sobre responsabilidad del gobierno federal; combatir la criminalidad; reducir los impuestos; apoyo a las familias y mejora del sistema sanitario- . El modelo federal que promueve el gobierno HARPER se identifica con un sistema federal flexible, con un federalismo de apertura, "que facilitará la implicación provincial en ámbitos de actuación federal donde éstos se hallen afectados y cuyos principios se concretarán en una Carta de Federalismo abierto" ${ }^{69}$. ¿Qué se ha de entender por un federalismo flexible y abierto?

El análisis de los discursos del Trono, leídos por la Gobernadora General de Canadá Michaëlle Jean, el 4 de abril de 2006 con motivo de la apertura de la 39. ${ }^{a}$ Legislatura y el 19 de noviembre de 2008, en la apertura de 40. ${ }^{a}$ Legislatura, así como la segunda sesión de la misma el 26 de enero de 2009, ofrecen el mejor referente para su exposición y análisis ${ }^{70}$.

El objetivo es alcanzar un "Québec más fuerte en un Canadá mejor". Para su implementación la percepción conservadora del federalismo como un sistema flexible significa: 1) Extraer todos los beneficios de la experiencia y de los expertos que las Provincias y los Territorios puedan aportar al diálogo

2003, tras las presidencias de Lucien Bouchard (1996-2001) y Bernard Landry (2001-2003). A partir de ese momento el Partido Liberal de Quebec ocupará el gobierno, siendo su presidente desde el 29 de abril de 2003 Jean Charest. Las últimas elecciones fueron el 8 de diciembre de 2008. Los partidos que obtuvieron representación parlamentaria fueron el Partido Liberal de Quebec, de Jean Charest con 66 diputados, el Partido Quebequés, dirigido por Pauline Marois con 51 diputados, Acción democrática de Quebec, de Mario Dumont con 7 diputados, y Quebec Solidario, que tiene solo un diputado. Cfr. <http://www.assnat.qc.ca/fra/Membres/index.html>. En lo que concierne a la Cámara de los Comunes de Ottawa, las elecciones de 2000 y 2004 dieron continuidad a la mayoría liberal, liderada por Jean Chrétien hasta el año 2003 y, posteriormente, por Paul Edgar Philip Martin, hasta febrero de 2006, precisamente en ese año las urnas catapultaron a la presidencia al partido conservador.

68 Los conservadores obtuvieron 143 escaños, lejos de la mayoría que se cifra en 155 . El Partido liberal confirmó su desplome, descendiendo a los 77 diputados — perdió 26 escaños-, el Bloque Qubequés se mantuvo, aunque reduciría dos escaños quedando su presencia en 49 diputados, de modo que los mejores resultados correspondieron al NDP (New Democratic Party), socialdemócratas, con 36 escaños, y a los verdes, que a pesar de obtener un $7 \%$ de votos se quedaron a las puertas de conseguir un escaño. Cfr. <http://www.parl.gc.ca>.

69 SIMEON, R. y NUGENT, A., "Parliamentary Canada and Intergovernmental Canada: Exploring the tensions", en BAKVIS, H., y SKOGSTAD, G., Canadian federalism. Performance, effectiveness and legitimacy, ob. cit., pág. 107.

70 Cfr. http://www.sft-ddt.gc.ca. 
nacional; 2) Respeto a los ámbitos competenciales provinciales; 3) Limitar el recurso al poder federal de gasto; 4) Establecer un mecanismo formal que canalice las posturas provinciales en la formalización de una posición canadiense en las organizaciones y en las negociaciones internacionales, cuando el contenido de dichos acuerdos repercuta en las Provincias; 5) Liberar a Québec de la trampa de la polarización; 6) Invitar a Québec a formar parte de la UNESCO; 7) Acorde con un concepto de "federación que camine paralela a las necesidades cambiantes de la sociedad canadiense" se propugna una revisión del sistema electoral y de las instituciones democráticas, particularmente del Senado, aspirando a que éste «refleje mejor tanto los valores democráticos de los canadienses como las necesidades de las regiones de Canadá".

El fantasma de la crisis $^{71}$, la ideología conservadora y las necesidades de reformar las instituciones ${ }^{72}$ son los tres pilares sobre los que se erige esta percepción, aparentemente, abierta del federalismo. Sin lugar a dudas, uno de los aspectos que más tensiones ha suscitado es la propuesta de reforzar la confederación, procediendo a "limitar el poder federal de gasto de modo que todo nuevo programa de coste compartido en un área competencial exclusiva provincial requerirá el consentimiento de la mayoría de las provincias para salir adelante. Igualmente, las provincias no participantes pueden optar a salir con una compensación, asegurándose la ejecución de programas o iniciativas compatibles" ${ }^{73}$. Estaríamos ante una respuesta neoconservadora a uno de los males endémicos de toda federación, incluida la canadiense, el localismo, el parroquialismo con el que se conciben las relaciones económicas y provinciales, buscando siempre favorecer a los de casa. Frente a este problema, entender que si el poder federal no recurre a su poder de gasto, para no entrometerse en la exclusividad provincial, el agradecimiento se tornará en una minoración de las trabas a la unión económica nacional es algo demasiado simple, demasiado utópico, demasiado incré́ble. En ese álgido debate, Tom Kent, ha sido tajante: "La Constitución no limita, nunca ha limitado el poder de gasto federal ${ }^{74}$. Lo que subyace es un temor, compartido por todos

71 El discurso del Trono de 2009 ha hecho especial hincapié en "estos tiempos inciertos, cuando el mundo está amenazado por una economía convulsa, resulta imperativo que trabajemos juntos, que estemos unos al lado de otros y nos esforcemos en lograr una mayor solidaridad" (pág.1). En consecuencia, "la agenda del gobierno y las prioridades del Parlamento deben adaptarse y afrontar esta profunda crisis. Anteriores presunciones deben ser probadas y viejas decisiones deben ser retocadas" (pág. 2). Speech from the Throne. To open de second session of the fortieth Parliament of Canada, 26 de enero de 2009. Library and Archives Canada Cataloguing in Publication, 2009.

72 Especialmente, la reforma del Senado — mandato que no supere los 8 años, designación por los electores y aplicación de igual régimen ético que la Cámara de los Comunes- y la representación en la Cámara de los Comunes de Ontario, Columbia Británica y Alberta. Protecting Canada's future. Speech from the Throne 2008.

73 Ibidem, ídem.

74 KENT, T., "The Harper Peril for Canadian Federalism", en Policy Options, febrero 2008, pág. 12. 
los Estados, a que la coyuntura económica se utilice para minorar avances sociales, en el caso canadiense plasmados en el SUFA (Social Union Framework Agreement). Lo preocupante es que se intente avanzar dogmáticamente en el federalismo, impregnando de opacidad alguno de sus irrenunciables principios fundacionales ${ }^{75}$. El futuro dira...

\section{REFLEXIÓN FINAL: PRINCIPALES RETOS PARA EL FUTURO DEL FEDERALISMO CANADIENSE}

"En estos tiempos inciertos» ${ }^{76}$, el futuro del Estado federal canadiense es, como cualquier otro, impredecible ${ }^{77}$. Sólo nos atrevemos a anticipar las dos grandes cuestiones que presumiblemente protagonizarán los debates políticos y jurídico-constitucionales de Canadá en su inmediato futuro: la reiterada tensión entre Quebec y el Gobierno Federal y el no menos importante tema de la identificación y status diferenciado de las naciones aborígenes, cada vez más concienciadas de su singularidad, y alentadas en sus demandas por los logros quebequeses.

En lo que se refiere a la integración/desintegración de Quebec en Canadá, cabría anticipar cinco escenarios posibles a través de los cuales se podría canalizar la solución a la tensa situación que tradicionalmente ha marcado las relaciones de Quebec con el resto de Canadá78:

— Un referéndum que cumpla con los requisitos señalados por la Clarity Act.

- Una declaración unilateral de independencia, que vendría a ignorar por completo la posición del legislativo federal y del Tribunal Supremo.

- Una estrategia ambivalente, similar a la desarrollada en 1995. La conjunción de la opción de la soberanía/independencia culminada con un tratado de asociación política y, sobre todo económica, con Canadá.

- Un proceso con diferentes etapas donde a través, básicamente, de sucesivos referenda, la posición política de Quebec alcance algún grado de sanción jurídica, por parte de la federación y, fundamentalmente, que se refleje en la Constitución federal. Así, una reforma

75 Una crítica al federalismo abierto de HARPER, la hallamos en uno de los más recientes y omnicomprensivos estudios sobre federalismo canadiense. La opción de hacer menos transparente al federalismo, se habla de la "aversión de Harper a las reuniones de primeros ministros" y de un inquietante diseño "unilateral" de la federación. BAKVIS, H., BAIER, G. y BROWN, D., Contested federalism. Certainty and ambiguity in the Canadian federation, ob.cit., págs. 129-130.

76 Speech from the Throne. To open de second session of the fortieth Parliament of Canada, 26 de enero de 2009, ob. cit, pág. 1.

77 MALLORY, J. R., "The five faces of federalism", en CREPEAU, P.-A. \& MACPHERSON, C.B., The future of Canadian Federalism, University of Toronto Press, Toronto, 1965, pág. 11.

78 RYAN, C., "Consequences of the Quebec Secession Reference. The Clarity Bill and Beyond", en C.D. Howe Institute Commentary, n. ${ }^{\circ}$ 139, abril, 2000, págs. 1-32. 
constitucional que ahonde las asimetrías quebequesas, podría articularse partir del procedimiento regulado por el art. 43 LC 1982, referido a la reforma de la Constitución de Canadá en relación a cualquier disposición que se aplique a una o más provincias, pero no a todas.

- Una indefinida dilación de la solución del conflicto, a través de un incierto proceso consultivo por parte de la población quebequesa y, sobre todo, el juego de alternancias políticas entre Québec y Ottawa.

En este estadio de la reflexión final no podemos soslayar que, por su parte, la clase política quebequesa ya escribió este futuro. Este aserto es válido no en el sentido más ampuloso y retórico, sino en el más formal y estricto, el referido a la existencia del Proyecto de Ley sobre el Futuro de Quebec (Project de Loi sur L'Avenir du Québec) ${ }^{79}$, que bajo la presidencia de Jacques Parizeau, se tramitó en la Asamblea Nacional de Quebec en 1995. Su propuesta redundaba en la conversión de Quebec en un Estado soberano, a través de un proceso democrático. El problema radicaba, radica y radicará en la integración de ese proyecto quebequés en el proyecto canadiense del gobierno federal y de las restantes provincias. En esta línea no podemos cerrar los ojos ante las crecientes perspectivas de centralización del federalismo canadiense, explicitadas en los programas federales de gasto, transformación, "reforzada y legitimada por el mundo neoliberal de mundialización" " que chocará frontalmente con las pretensiones de las minorías políticas de Canadá, quebequesa o autóctona, de acabar con el Estado federal canadiense tal y como hoy se conoce.

La segunda cuestión a considerar en el devenir de la federación canadiense se refiere a la cuestión aborigen. Hasta ahora agazapados a la sombra de la dialéctica relación Ottawa-Quebec, los aborígenes han protagonizado la página de conflictos del federalismo canadiense. La búsqueda de un tratamiento específico a los descendientes de los primeros habitantes de Canadá, que no magnifique sus privilegios con respecto a los demás ciudadanos canadienses es el principal reto a afrontar. Así, nos adherimos a la opinión de Ronald Watts para quien "existen casos en los que la asimetría es el único camino para resolver las diferencias entre los impulsos de centralización y descentralización existentes en las diferentes partes de la federación. Esta es una posible aproximación a la caracterización a otorgar a las unidades de autogobierno aborígenes. Estos grupos no requieren necesariamente ser uniformes, aunque más allá de un cierto grado de asimetría se podría alcanzar

79 Project de Loi n. ${ }^{\circ}$ 1, Trente-cinquième législature: Loi sur L'Avenir du Québec, Québec, Editeur officiel du Québec, 1995. Este Proyecto de Ley se envió a los domicilios de los electores durante la campaña del referéndum de 1995, acompañado del Acuerdo entre el Partido Quebequés, el Bloque Quebequés y la Acción Democrática de Quebec, de 12 de junio de 1995, en el que se sancionaba su unión a favor del voto afirmativo en dicha consulta.

80 LAJOIE, A., "L'avenir du fédéralisme canadien: implosion lente ou rapide?", en Centro di Ricerca e formazione sul Diritto Costituzionale Comparato. Agora on line, <http://www.unisi.it>. 
una situación contenciosa "81. Si el futuro se de las relaciones Canadá y Quebec se definiera conforme a las previsiones que se han inclinado por la más depurada dualidad ${ }^{82}$, aún en ese contexto el problema de los aborígenes, de los nativos, sería más incisivo porque pasaría a ocupar un primer plano de discusión en cada uno de los dos polos.

Hasta aquí esta subjetiva presentación de los aspectos más relevantes del diseño constitucional y del desarrollo de la federación canadiense. La nueva cara del federalismo canadiense llevará impresas muchas de las cuestiones que han protagonizado los 142 años de andadura del mismo, pero, de modo indefectible, se producirán nuevas incorporaciones, como la importancia del desarrollo sostenible, la estrategia con respecto al Ártico canadiense, la firmeza de Canadá en un mundo global, la consolidación de muchos de sus logros (Vancouver es la ciudad distinguida como la que mejor se vive del mundo por EUI, el liderazgo canadiense en capacidad tecnológica). Ante esta tesitura, es conveniente no olvidar que "el éxito de Canadá se debe en gran medida a su carácter federal, ${ }^{83}{ }^{\circledR}$.

Trtze: Canadian constitutional design and its implementation: from Macdonald to Harper.

AвSTRACT: This article reflects the evolution of Canadian Federalism from British North America Act (1867) nowadays. The main issue is to analyse how different models of federalism have been succeded: "dual federalism" according to the division of powers in the Constitution; "colonial federalism" in the relation between national and provincials powers following the model of the Empire; "asymmetrical federalism" in the study how Constitution shows the different component units of Canadian society; "renewed federalism" as main intention to solve the integration of Canada; "decentralized federalism" the Supreme Court's vision of federalism; "executive and legislative federalism", referring to different types of intergovernmental relations; "separatist federalism" the last items in Quebec's adaptation and "open federalism", the Harper's vision of Canadian federalism.

81 WATTS, R. L., "Federal systems and acommodation of distinct groups: a comparative study of institutional arrangements", Working Paper 1998 (3), Institute of Intergovernmental Relations, Kingston, 1998, pág. 20.

82 Philip RESNICK postula una redefinición de Canadá sobre la «base de dos naciones sociológicas, garantizando a los gobiernos del Canadá anglófono y a Quebec la mayoría de los poderes ahora detentados por el gobierno federal. Tendrán Constituciones separadas y presumiblemente Cartas de Derechos diferentes para cada una de las dos naciones, con disposiciones que no necesariamente han de ser idénticas". RESNICK, P., Toward a Canada-Quebec Union, McGillQueen’s University Press, Montreal, 1991, pág. 104.

83 BAKVIS, H., Baier, G. y BROWN, D., Contested federalism. Certainty and ambiguity in the Canadian federation, ob. cit., pág. 260.

${ }^{\circledR}$ La redacción de este artículo tiene ha recibido el apoyo de los Proyectos SEJ 2007-64886/ JURI "Ciudadanos, nuevas tecnologías y toma de decisiones" y DER 2008-00185 JURI "Pluralidad de ciudadanías y participación democrática». Las estancias en las Universidades canadienses de Montreal, Laval y Queen's han sido determinantes en su confección. Agradezco a los profesores Ronald Watts y José Woehrling sus consejos para la redacción de este artículo, del que no obstante me responsabilizo íntegramente. 
RESUMEN: Este artículo analiza la evolución del federalismo canadiense desde la aprobación de la Ley de América del Norte Británica, en 1867, hasta nuestros dias. Para ello ba utilizado como guía distintos tipos de federalismo que se han ido identificando en ese recorrido: el "federalismo dual" que refleja la concepción federal de los padres de la confederación canadiense y que se plasma en el reparto competencial entre la federación y las provincias; "federalismo colonial" que traduce en el ámbito interno de las relaciones centro periferia el modelo del Imperio Británico con sus colonias y que se concreta en un predominio del núcleo federal; "federalismo asimétrico" identifica la recepción constitucional de hechos diferenciales dentro de la federación canadiense; "federalismo renovado", hace referencia al intento que materializó la Ley Constitucional de 1982 de fortalecer la federación reinsertando a Quebec en el proyecto; "federalismo descentralizado" revisa el esfuerzo desde la revisión judicial de buscar un equilibrio entre todos los componentes de la federación; "federalismo ejecutivo y federalismo legislativo", ahonda en la importancia de las relaciones intergubernamentales en el desarrollo del federalismo canadiense como alternativa viable a la rigidez constitucional; "federalismo separatista", se preocupa de cómo se ha tratado la cuestión quebequesa en la última década; "federalismo flexible" analiza la versión federal del actual Primer Ministro de Canadá, Stephen Harper.

Key words: Constitutional Law. Canada. Federalism. Division of powers . Judicial review. Intergovernmental relations. Dual federalism. Colonial federalism. Asymmetrical federalism. Renewed federalism. Decentralized federalism. Cooperative federalism. Competitive federalism. Open federalism.

Palabras clave: Derecho Constitucional. Canadá. Federalismo. Reparto competencial. Revisión judicial. Relaciones intergubernamentales. Federalismo dual. Federalismo colonial. Federalismo asimétrico. Federalismo renovado. Federalismo descentralizado. Federalismo cooperativo. Federalismo separatista. Federalismo flexible. 